NASA Technical Memorandum 86811

NASA-TM-86811

19860016805

\title{
Summary of Results of NASA F-15 Flight Research Program
}

Frank W. Burcham, Jr., Gary A. Trippensee, David F. Fisher, and Terrill W. Putnam

\section{FOR REFERENCE}

HOT TO BE TAEDI FROM TIIS ROOU

\section{LIBRARY COPY}

April 1986

Whiti 109897

LANGLEY RESEARCH CENTER

LIBRARY, NASA

HAMPTON, VIRGINIA'

\section{N/Sก}

National Aeronautics and

Space Administration 
NASA Technical Memorandum 86811

\section{Summary of Results of NASA F-15 Flight Research Program}

Frank W Burcham, Jr, Gary A Trippensee, David F Fisher, and Terrill W Putnam Ames Research Center, Dryden Flıght Research Facility, Edwards, Californıa

\section{N/Sก}

National Aeronautics and

Space Adminıstration

Ames Research Center

Dryden Flight Research Facility

Edwards, Calıfornı 93523 
SUMMARY OF RESULTS OF NASA F-15

FLIGHT RESEARCH PROGRAM

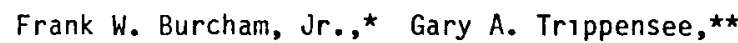

David F. Fisher, ${ }^{\dagger}$ and Terrill W. Putnam ${ }^{\neq}$ NASA Ames Research Center

Dryden Flight Research Facility

Edwards, Calıfornia

\section{Abstract}

NASA conducted a multidisciplinary flight research program on the F-15 alrplane. The program began in 1976 when two preproduction a1 $\mathrm{r}$ planes were obtalned from the U.S. Air Force. Major projects involved stability and control, handing qualities, propulsion, aerodynamics, propulsion controls, and integrated propulsionflight controls. Several government agencies and aerospace contractors were involvod. In excess of 330 flights were flown, and over 85 papers and reports were published. This document describes the overall program, the projects, and the key results. The F-15 was demonstrated to be an excellent flight research vehicle, producing high-quality results.

\section{Nomenclature}

ADECS adaptive engine control system

AEDC Arnold Engineering and Development Center

AJ jet nozzle area

BTL boattall angle

BUC backup control

CAS control augmentation system

CENC convergent exhaust nozzle control

C.I.P. component improvement program

CIVV compressor inlet variable vanes

$C_{p} \quad$ pressure coefficient

DEEC digital electronic engine control

DEFCS digital electronic fioght control system

DTMM maximum-minimum total pressure distortron factor

EMD engine model derivative

\footnotetext{
*Assistant Chref, Vehicle Technology Branch, Member AIAA.

$\star \star F-15$ Project Manager.

†Aerospace Engineer, Member AIAA.

${ }^{*}$ Chief, Vehicle Technology Branch, Member AIAA.

This paper is declared a work of the U S Government and is not subject to copyright protection in the United States
}

EPR

FDA

FTIT

H

HIDEC

HาMAT

L

LOD

M

N1

N2

PB

PLA

PS2

PS6

PT2

PT6

$\sqrt{\bar{p}_{s}^{\prime 2}}$

q

RCVV

$\operatorname{Re}$

ReT

TT2

U

USAF

WAC

WF

WFGG engine pressure ratio, PT6/PT2

fault detection and accommodation

fan turbine inlet temperature

altitude

highly integrated digital electronic control

highly maneuverable alrcraft technology

arplane length

light-off detector

Mach number

fan rotor speed

compressor rotor speed

burner pressure

power lever angle

engine-inlet static pressure

turbine discharge static pressure

fan inlet total pressure

mixed turbine discharge total pressure

surface pressure root-mean-square pressure fluctuation amplitude

dynamic pressure

rear compressor variable vanes

Reynolds number

transition Reynolds number

engine-inlet total temperature

velocity

U.S. Air Force

corrected fan airflow

fuel flow

gas generator fuel flow 


$\begin{array}{ll}\text { W.T. } & \text { wind tunnel } \\ X / L & \text { normalized axial distance } \\ X & \text { axial distance } \\ \alpha & \text { angle of attack } \\ B & \text { angle of sideslip } \\ \Delta, \delta & \text { change in parameter } \\ \phi & \text { circumferential angle } \\ v & \text { kinematic viscosity }\end{array}$

Subscripts

e edge conditions

$\infty$ freestream conditions

Introduction

Flight research is a key tool in validating the methodology of aircraft design and development. Flight data provide the basis for validating analytical design codes, ground test and wind tunnel test techniques, and flight simulation techniques. Flight demonstration is also an important part of the development process in which new concepts must be demonstrated and evaluated before being included in production airplanes. 1

Over the last decades, NASA has maintained a series of programs, in which filght research has been conducted in appropriate areas. In the mid1970s, the NASA Ames Research Center's Dryden Flught Research Facility (Ames-Dryden), in cooperation with the U.S. Air Force (USAF), acquired two F-15 airplanes and began a multidisciplinary flight research program that continued for almost $10 \mathrm{yr}$. The F-15 represented a new generation of high-performance airplanes with excellent transonic maneuverability and high thrust-to-weight ratio. Areas of research included basic stability and control, handling qualities, buffet, propulsion system performance, engine-inlet compatibility, inlet-airframe integration, nozzle-afterbody integration, propulsion control, advanced engine development and test, integrated propulsion-flight control, and aerodynamic experiments, including tests of a 10-deg cone and space shuttle tiles. In addition, new cockpit display methods and partial pressure suits were tested, and new measurement systems were tested and evaluated. To provide correlation with the flight data, tests were run on wind tunnel scale models at the NASA Langley Research Center and at the Arnold Engineering and Development Center (AEDC), and the engines were tested at the NASA Lewis Research Center. Other wind tunnel tests were also conducted. In all, about 85 technical reports and papers were published. This document presents a summary of the projects conducted and some of the key results obtained.

\section{Description of the F-15 Airplane}

The F-15 (Figs. 1 and 2 ) is a high-performance air-superiority airplane with a high thrust-toweight ratio and excellent transonic maneuverability. It is manufactured by MCDonnell Aircraft Company and has a maximum Mach number capability of 2.5. The airplane has a low aspect ratio shoulder-mounted w1ng with $45-$ deg sweep and twin vertical tails. It 15 powered by two afterburning turbofan engines, each supplied with air by a variable-geometry inlet. The two alrplanes used in the NASA flight research program were the F-15A-2 airplane (serial number 710281), the preproduction propulsion test airplane, and F-15A-8 aurplane (serial number 710287), the preproduction high-angle-ofattack and spin test airplane. Both airplanes were single-seat airplanes. The F-15A-2 airplane (F1g. 1) retained the original preproduction wing planform, while the F-15A-8 had raked wingtips (Fig. 2) which is the production configuration.

The F-15 flight control system consists of horizontal talls for pitch control, rolling tails and allerons for roll, and dual rudders for yaw. A fully mechanical flight control system is augmented by a dual-channel limited-authority analog control augmentation system (CAS) in all axes.

The F-15 inlet (Fig. 3) is a variable-geometry design with external compression. It incorporates variable-capture first ramp, with the cowl hinged at a rotation point as shown in Fig. 3. The second, third, and diffuser ramps are iınked together. The bypass door exits air from a throat slot bypass. A digital inlet control system positions the ramps and the bypass as a function of sensed variables.

The F100-PW-100 engrne (F1g. 4) powers the F-15 airplane. This engine is a low-bypass afterburning turbofan built by Pratt and Whitney. It features a three-stage fan driven by a two-stage low-pressure turbine and a nine-stage compressor driven by a two-stage high-pressure turbine. The mixed flow augmentor incorporates five segments and a variable-area nozzle. These station designations are also shown in Fig. 4.

\section{Summary of Flight Research Programs}

Numerous flight research programs have been conducted using the two F-15 airplanes. The major research programs (Fig. 5) are summarized here and are later discussed in more detail.

F-15A-8 was acquired in 1976 and was used to conduct basic studies of handling qualities, stability and control, aerodynamic buffet, tracking, and overall agility. At the same time, F-15A-2 was flown for an engine-inlet compatibility study. Following completion of this effort, several flights were flown to evaluate changes to the F100 engines in the component improvement program. 
F-15A-2 was grounded for an instrumentation phase, and the test engines were taken to NASA Lewis Research Center for calibration tests and evaluation. F-15A-8 was flown during this period by several NASA pilots to evaluate airplane flying qualities characteristics. In mid-1977, F-15A-2 was flown for the evaluation of the inlet-airframe and nozzle-aft-engine interaction characteristics. During this period, the calibrated engines were installed, the in-flight thrust was calculated, and a new thrust calculation al gorithm was evaluated. Data were acquired for comparison of wind tunnel and flight measurements, and special flight test techniques were developed to improve the match between wind tunnel and flight test conditions.

In early 1978, the AEDC 10-deg transition cone was mounted on the nose of $F-15 A-8$ and flown at Mach numbers up to 2.0. This cone had been used to calibrate 23 American and European wind tunnels for freestream disturbance levels by measuring the laminar to turbulent transition location. Two years later, a similar cone was flown at a local angle of attack of 11 deg at Mach numbers of 0.6 , 1.2, and 1.8. At this angle of attack, symmetric vortices formed on the leeward side of the cone. The pressure distributions and lines of separation were obtained. The data quality was enhanced by the use of special cockpit displays that made it possible to hold very steady flight conditions at high Mach number.

In late 1979, the flight integrity of the space shuttle thermal protection tiles needed to be verified. The F-15A-2 airplane was used, with four different tile samples mounted at various locations on the airplane. As a result of these tests, several changes were made in the tile system. At the same time, an engine-inlet static pressure (PS2) sensor was flown. Following the shuttle tile and PS2 tests, F-15A-2 airplane was retired from service and is now on display at Langley Air Force Base.

In late 1980, on the basis of NASA test experience with the F100 engine, the USAF and Pratt and Whitney expressed interest in a flight evaluation of the newly developed digital electronic engine control (DEEC) system. This engine was installed in the F-15A-8 airplane and flown in a five-phase flight evaluation that continued from 1981 to 1983 . During the DEEC testing, an experiment was conducted to evaluate an in-flight structural deflection measuring system. This system was mounted on the right wing of the F-15A-8 airplane and evaluated at a series of flight conditions.

In 1983, the USAF was developing an upgraded model of the Fl00 engine, the F100 engine model derivative (EMD). Again, the desire for an early flight evaluation led to a joint NASA and USAF program to evaluate the F100 EMD. The tests began in March 1983 and continued into 1986.

In 1985, the Highly Integrated Digital Electronic Control (HIDEC) program was initiated to investigate the benefits of engine-flight control integration. A digital flight control system was developed and tested. The DEEC was modified to accept commands from the HIDEC computer to trade engine stall margin for increased thrust when the full stall margin was not required. The system was installed in the airplane in early 1986.

Recently, the F-15A-8 arrplane was again used in the test-bed role - in this case, to conduct research on supersonic natural laminar flow. A smooth glove was installed on the right wing, and special instrumentation was installed to determine the extent of laminar flow on a swept wing at supersonic speeds. The $F-15 A-8$ airplane was also used to conduct studies on the acoustic characteristics of twin jets.

\section{Flight Test Trajectory Guidance}

A capability developed early in the F-15 flight research program has been a key part of the research output of the program. The initial program objectives included several projects in which comparisons of wind tunnel data with flight measurements were required. Previous experience in the YF-12 project pointed out the need for methods to improve the ability to achieve precise flight conditions. Therefore, a technique, called flight test trajectory gurdance (F1g. 6), was developed. As shown in Fig. 6(a), telemetry data were recelved from the alrplane, and a series of computations were performed in a ground computer. The appropriate guidance commands were generated and telemetered back to the airplane and displayed in the cockpit. In most cases, the pilot display was a modified course deviation indicator, such as that in Fig. 6(b). This device displayed pitch commands on the horizontal needle, bank angle commands on the vertical needle, and throttle commands on the side indicator. In some cases, additional information was required. For example, Fig. 6(c) shows the cockpit display of true angle of attack, true sideslip angle, true Mach number, engine airflow, and nozzle boattall angle as well. References 2 to 9 describe the flight test trajectory guidance system in more detail and also present the algorithms used to generate the guldance commands.

Stability and Control, Handling Qualities, Buffet, and Tracking

The initial research on F-15A-8 consisted of an evaluation of the stability and control, handing qualities, buffet characteristics, and the overall airplane tracking.10,11 Tasks included windup turns, gunsight tracking, and simulated alr-to-alr combat. Vortex flows that affect the high-angle-of-attack aerodynamics were studied in a water tunnel. 12

\section{0-Deg Transition Cone Experiment}

To evaluate the effects of wind tunnel turbulence on boundary layer transition, the F-15A-8 was used as a test-bed in a unique flight-to-windtunnel correlation experiment (F1g. 7). A sharp slender cone with an included angle of 10 deg and a length of approximately $3 \mathrm{ft}$ was mounted on the nose of the F-1SA-8 as shown in Figs. $7(a)$ and 7(b). This cone, known as the AEDC transition cone, was used previously in calibrations of 23 American and European wind tunnels. The same 
instrumentation and techniques were used to detect the onset and end of boundary layer transition and to document the pressure fluctuations in the wind tunnel and in flight.

Comparisons of surface pressure fluctuations for flight, lower noise wind tunnels, and higher nolse wind tunnels are shown in Fig. $7(\mathrm{c})$. The pressure fluctuation levels measured in the lower noise wind tunnels are about twice those measured in flight. The higher norse wind tunnel pressure fluctuations are an order of magnitude higher than the in-flight measurements.

Good correlation of the end of transition Reynolds number ReT was obtained between data from the lower turbulence wind tunnels and flight up to a Mach number of 1.2 , as indicated in Fig. 7(d). Above Mach 1.2, however, the correlation deteriorates, with the flight ReT being 25- to 30-percent higher than the wind tunnel ReT at Mach 1.6. Add1tional information on the transition cone tests may be found in Refs. 13 to 18.

\section{0-Deg Cone Separation Experıment}

The three-dimensional leeward separation about the 10-deg cone at a local angle of attack of 11 deg was investigated in flight on the F-15A-8; the results are summarized in $F_{1 g}$. 8. A facsimile of the AEDC transition cone was instrumented with static and dynamic pressures, as shown in Fig. 8(a), and the results were compared with wind tunnel data and numerical computations. The test conditions were at Mach $0.6,1.2$, and 1.8 and at $\operatorname{Re}$ between 7 and $10 \times 10^{6}$. Mean and fluctuating surface pressures were measured. By using obstacle blocks, skin friction magnitudes and separation line positions were obtained.

The mean static pressures from flight and wind tunnel were in good agreement. The computed results, as shown in Fig. 8(b), gave similar distributions but were silightly more positive in magnitude. The experimentally determined primary and secondary separation line locations compared closely with wind tunnel and computed results.19-21

The use of trajectory guidance was important in maintaining steady test conditions while acquiring data for the slender cone separation experiment. The Mach number, altitude, and angle of attack were maintained within strict limits at supersonic speeds in sustained turns, as indicated in Fig. $8(\mathrm{c})$.

\section{Engine-Inlet Compatibility Project}

There are several key questions in achieving compatibility between engines and inlets. These include the differences between wind tunnel and flight data, the effects of scale, the effects of Reynolds number, and the effects of filter cutoff frequencies used in data analysis. Another unknown is the effect of simulating an actual engrne with a "cold pipe" engrne simulator. To attempt to answer these questions, a comprehen- sive joint NASA and USAF project was conducted using the $F-15$.

Figure 9 outlines the engine-inlet compatibility research project. Data were avallable for a one-sixth scale model and a full-scale wind tunnel test model. The full-scale wind tunnel test model included a "cold pipe" engrne simulator, as well as an actual engine. All three inlets were instrumented with total pressure sensing arrays at the engine face location. Engine face distortion parameters from the wind tunnel tests were computed and compared with flight data. The highest inlet distortion was produced at extreme flight conditions, such as -10-deg angle of attack and $10-$ deg sideslip. The flight test trajectory gurdance technique was used to assist the pilot in attempting to achieve these conditions; an example is shown in Fig. 9(b).

The effects of Reynolds number as a function of model scale size are shown in Fig. $9(\mathrm{c})$. In general, the effects of increasing scale size and Reynolds number are favorable; pressure recovery increases, and turbulence and distortion decrease. The effects of filter cutoff frequency on the fan distortion and turbulence are shown in Fig. 9(d). The data provide a guide for selecting cutoff frequencies for future designs. Although not shown, the effect of replacing the simulated engine with an actual engrne in the full-scale wind tunnel test was to reduce the distortion and improve the engine-inlet compatibility.

Engine fan stability audits were conducted to evaluate the methodology of the engine manufacturers. Fan stalls were encountered at only a few extreme flight conditions. However, at these conditions, the stability audit stail margins were within approximately 5 percent of the measured values. Results are summarized in Refs. 22 and 23.

\section{Engine Calibrations}

Two of the F100 engines used in the flight research projects (engines P680059 and P680063) were calibrated at the NASA Lew1s Research Center's Propulsion System Laboratory for thrust and airflow.24-26 These calibration results were needed for subsequent inlet and nozzle flight research projects. In addition, a simplified gross thrust method and the engine manufacturer's in-flight thrust calculation routine were evaluated in the calibration. 27

Inlet-Airframe Integration Research Project

Another objective of the original F-15 program was the flight evaluation of inletairframe interactions. Strong and unforeseen inlet-airframe interactions had been observed on the YF-12 program. The F-15 inlet incorporates extensive variable geometry to maximize performance and, hence, provides an excellent research opportunity. Therefore, in a joint project with the USAF, the inlet of the F-15 
was instrumented, and extensive evaluation and comparison with the analytical ang wind tunnel data were conducted (Fig. 10).28-30

The wind tunnel model used in the project is shown in Fig. 10(a). It featured a complete airplane model with flowing inlets. The left inlet was mounted on a force balance, the right inlet was pressure instrumented, and the entire model was mounted on a force balance. The alrplane was instrumented with pressure ports located at the same position as on the one-sixth scale model. The pressure integration routines were carefully coordinated between the wind tunnel and flight data analyses.

Typical results are shown in Fig. 10(b) in which the inlet $11 \mathrm{ft}$ and drag for the wind tunnel pressure integrated and force balance data are compared with the flight data for a range of Mach numbers. The inlet drag measured in flight was lower than the wind tunnel data, while the $1 \mathrm{nlet} 11 \mathrm{ft}$ was in good agreement. The flightdetermined total inlet drag is shown in $F_{1 g} .10(c)$ and indicates the relative values of drag from the various sources. These results provided one of the first flight determinations of inlet drag.

\section{Nozzle and Aft Engine Integration}

The nozzle and aft engine integration results are summarized in Fig. 11. The left engine nozzle and afterbody were extensively instrumented with over 90 orifices, as indicated in Fig. 11(a). These orifice locations matched those of the 1/12th scale wind tunnel model tested at NASA Langley Research Center. Results are presented in Refs. 31 to 36. A typical comparison of flight to wind tunnel data at one orifice row, 1 liustrated in Fig. 11(b), shows good agreement at Mach 0.6, and poorer agreement at Mach 0.9 and 1.2 .

The overall nozzle drag, or axial force, plotted in Fig. 11(c), shows the strong effect of Mach and boattail angle. The variation of nozzle drag with Re in Fig. 11(d) shows the drag coefficient decreasing as Re increases. It was found that the effect of the falred-over inlets on the wind tunnel model was affecting the vortex flow over the upper part of the airplane and affecting the flow quality at the nozzle.

\section{In-Flight Thrust}

The two F100 engines that had been calibrated at the the NASA Lewis Research Center were flown in the F-15. These engines (P680059 and P680063) were instrumented to provide input data for the simplified gross thrust nethod and the in-flight

thrust calculation method. Results 37 showed that the simplified gross thrust nethod was a suitable alternative to more complex methods for determining in-flight gross thrust.

\section{Shuttle Thermal Protection System Evaluation}

During the first ferry flight of the space shuttle orbiter, Columb1a, on the top of the Boeing 747 carrier alreraft, some of the thermal protection system tiles and gap fillers loosened or migrated. This unanticipated occurrence at modest flight conditions initiated a reassessment of the effects of arrloads on the thermal protection system during launch and reentry.

F-15A-2 alrcraft was used to assist in certification of the tiles prior to the first shuttle launch (Fig. 12). In-flight aerodynamic loads tests of four shuttle tile areas, shown in Fig. 12(a), were conducted. The objective of the tests was to demonstrate the performance of the tiles and gap fillers at dynamic pressures up to 1.4 times the predicted launch loads. The four articles tested on the F-15A-2 aircraft were mounted in two separate locations, as indicated in Fig. 12(b). Three test articles were mounted on the the right wing, and the other was mounted on the left wing glove. The wing leading edge, window post, and vertical stabilizer tile articles were mounted on the wing, Fig. 12(c) shows the vertical stabilizer article. The shuttle wing glove test article was mounted on the F-15A-2 wing glove, as shown in Fig. 12(d).

Flight test trajectory guidance was used to assist the pilot in flying flight profiles that would provide the proper simulated airloads to the test articles. The test results provided a data base for the verification of wind tunnel data and analytical predictions. In general, the F-15A-2 simulations of the predicted maximum ar rloads expected on the shuttle were good. The testing did reveal two deficiencies that required redesign. The gap filler assembly and the tile carrier plate assembly were redesigned. Also, a modification of the window post closeout tile was made because the pressure under the window post was higher than predicted. Both modifications were tested on the F-15A-2, and modifications were accomplished on the shuttle prior to its first flight. 38

\section{Engine-Inlet Static Pressure}

Engine-inlet pressure is a key parameter needed for control of advanced engines. This parameter may be measured directly by total pressure probes, however, total pressure distortion introduces wide variations in the readings or requires a large number of measurements to be made. An alternative is to measure static pressure. Wall static pressures also are sensitive to distortion, however, a stream static pressure at the engine hub has shown promise of providing a useful engine control signal. Therefore, NASA, in conjunction with Pratt and Whitney, has conducted studies39-41 of an engine inlet static pressure (PS2) probe (F1g. 13).

Figure 13(a) shows the hemispherical head PS2 probe on the F100 engine. A 35-probe total pressure array was installed in the engine-inlet guide vanes to provide a correlation with the PS2 probe, as indicated in Fig. 13(b). The ratio of the average tan inlet total pressure (PT2) to PS2 was determined in a number of flights. A manual inlet control system was used to move the inlet ramps to off-schedule positions to increase distortion up to the point of engine stall. Typical 
results are shown in Fig. 13(c). The effects of distortion produce a repeatable change in the ratio of the average PT2 to PS2, thus providing a very useful control system signal that is used in the DEEC.

\section{DEEC Evaluation}

The DEEC is a full-authority digital system developed to replace the hydromechanical unified fuel control and the supervisory engine electronic control on the F100 engine. The DEEC (Frg. 14) was installed on an $F 100$ engine and flown in the F-15A-8 in a five-phase joint NASA, USAF, and Pratt and Whitney evaluation.42-67 The DEEC provides control of the compressor inlet variable vanes (CIVV), the rear compressor variable vanes (RCVV), the start bleeds, the mann combustor fuel flow, the augmentor fuel flow, and the variable area nozzle, as indicated in Fig. 14(a). The DEEC is a singlechannel system with selected input-output redundancy and a simple independent hydromechanical backup control, as shown in Fig. 14(b).

The DEEC incorporates closed-loop control of engine pressure ratio (EPR) and airflow. Th1s eliminates the need for periodic ground trim runs to keep the engine operating within desired limits. It also provides closed-loop starting capability. This capability allowed the Fl00 airstart envelope to be improved as shown in Fig. 14(c), with airspeed reductions of 75 knots.

The DEEC also incorporates improved augmentor control that results in significant improvements in augmentor lighting capability. Figure 14(d) shows the high-altitude low-airspeed idle-tomaximum power throttle transient success at the end of the fourth phase of testing, and also shows the lines of success from previous tests. The overal1 improvement is in excess of $10,000 \mathrm{ft}$. The occurrence of augmentor assoclated stalls was greatly reduced.

In addition, the DEEC has extensive fauit detection and accommodation (FDA) capability. In excess of 160 faults can be detected, and many of these can be accommodated by an alternate $\operatorname{logic}$ path or reduced capability operation. To evaluate the FDA capability in flight, a series of valves and sivitches were installed on the engine to introduce simulated fallures to the DEEC in flight, as indicated in Fig. 14(e). The FDA logic was evaluated over the test conditions shown in Fig. 14(f) in the fifth phase of DEEC testing. Several problems were identified in detecting fallures but, once detected, operation with falled sensors was very successfut.

The DEEC evaluation was highly successful, leading to full-scale development and produc$t i o n$ of an improved version of the F100, the F100-PW-220 engine.

\section{Deflection Measuring System}

During the DEEC evaluation, a brief flight evaluation of a deflection measuring system was conducted. This system, designed to provide direct readout of structural deflections, was needed for the highly maneuverable aircraft technology (HIMAT) and $X-29$ programs, in which composite structural materials and aeroelastic tailoring were employed. The $F-15 A-8$ was used to develop, check out, and evaluate the operation of the deflection measurement system. The system flown on the F-15A-8 (Fig. 15), consisted of light-emitting diode targets and diode receiver array mounted on the F-15 wing upper surface, as indicated in Fig. 15(a). The upper wing was painted black to minimize the effects of sunlight on the system. The schematic view of the system in Fig. 15(b) shows the lightemitting diode targets that are sequentially illuminated and the diode receiver that senses the deflection. The system was checked out at various levels of normal acceleration and was validated for the HiMAT and $x-29$ programs.

\section{F100 EMD Flight Evaluation}

An advanced version of the $F 100$ engine, the F100 EMD was evaluated in the F-15A-8. The EMD program is a USAF program to provide significant improvements to existing engines. The USAF developed the F100 EMD, in conjunction with Pratt and Whitney (company designation PW1128), and formulated a joint program with NASA to conduct a flight evaluation (Fig. 16). The advanced features of the F100 EMD, shown in Fig. 16(a), include a redesigned fan with higher airflow and pressure ratio, a revised combustor, single crystal turbine blades and vanes, a DEEC, and a redesigned 16-segment augmentor.

The F100 EMD engine has about 15 percent more thrust than the standard F100. Th1s improves the performance of the F-15 significantly. Figure $16(b)$ shows that the time to accelerate from Mach 0.8 to 2.0 is reduced by 25 percent. The alrplane also has supersonic cruise capability (Mach 1.15) at intermediate power with the F100 EMD engrnes. The 16-segment augmentor, which replaced the 5-segment augmentor of the F100, exhibited improved operation. The smaller pressure pulses associated with the more numerous segments completely eliminated augmentor induced stalls in the flight evaluation, as indicated in Fig. 16(c).

During the flight evaluation, compressor stalls were encountered during intermediate-toidle power throttle transients at extremely high-altitude and low-alrspeed conditions. These stalls were not predicted by analytical or altitude facility test results. Special highresponse pressure probes were installed at the fan discharge; they demonstrated that, under certain conditions, flow separation occurred and resulted in increased distortion to the compressor. The reason that the altitude facility results could not duplicate the flight results is not clear. More information on the F100 EMD evaluation is presented in Refs. 68 to 71 .

\section{HIDEC Project}

The objective of the HIDEC project is to evalwate the performance improvements and mission effectiveness increases that result from propulsion and flight control integration.72-86 This will be accomplished on the F-15A-8 by integra- 
ting the flight control and engune control systems (Fig. 17). As shown in Fig. $17(\mathrm{a})$, the F-15A-8 has been equipped with a digital electronic flight control system (DEFCS), the F100 EMD engines with DEECs, and digital interface and bus control equipment to permit the flight controls and engine controls to communicate. An uplink from ground-based computers permits control computations to be made in general-purpose computers in higher order languages and then uplinked to the airplane.

One of the HIDEC modes is an adaptive engine control system (ADECS) mode in which engine stall margin is traded for increased performance as a function of flight conditions. Typically, engine stall margin is set to accommodate the worst case combination of engine and inlet generated disturbances. When either the engine or inlet disturbances are less severe, additional performance may be obtained in the form of increased thrust, decreased fuel consumption, or increased engine $11 \mathrm{fe}$. Figure 17(b) shows a block diagram of the ADECS mode. Inputs from the DEFCS representing airplane attitudes, rates, and pilot inputs are used to compute the current and predicted inlet distortion and, hence, the fan stall margin requirements. The DEEC provides information on the engine status from which the required stall margin is computed. The allowable EPR is calculated, and the difference between the current and the allowable EPR is then transmitted to the DEEC. Thrust increases are predicted to be in the 5 - to 10-percent range, with fuel flow reductions in the 5- to 15-percent range, as shown in Figs. 17(c) and $17(d)$.

\section{Supersonic Laminar Flow}

The occurrence of natural laminar flow on airfolls is of interest in drag reduction efforts. In particular, there is little or no information on the extent of natural laminar flow on swept wings at supersonic speeds. The $F-15 A-8$ was used as a test-bed airplane to investigate supersonic laminar flow (Fig. 18). A very smooth fiberglass glove was installed on the leading edge of the right wing, as shown in Fig. 18(a). Pressure instrumentation installed in the glove measures the pressure gradient, and hot film anemometers were used to determine the extent of laminar flow, as indicated in Fig. 18(b). Flight results confirmed that small amounts of natural laminar flow exist at supersonic speeds at certain conditions.

High-Altitude Partial Pressure Protective System

As an alternative to cumbersome pressure suits, the Royal Air Force high-altitude partial pressure protective system (jerkin) was evaluated in the F-15A-8 (Frg. 19). The jerkin system, shown in Fig. 19(a), consists of a pressure jerkin torso garment, ant1-gravity trousers, a pressure demand mask, and a pressure regulator. The system 87 provides the pilot with safe getdown capability in case of cockpit depressurrzation at altitudes up to $60,000 \mathrm{ft}$, as ind 1cated in Fig. 19(b). The jerkin has been used for flights at high altitudes in the supersonic laminar flow project and in high-altitude engine and augmentor evaluations.

\section{Flight and Publication Rates}

The flight rates of $F-15 A-2$ and $F-15 A-8$ are shown in Fig. 20. Prior to its retirement, F-15A-2 flew 140 research flights with an average of 28 flights/yr. F-15A-8 has flown 193 flights for an average of 19 research flights/yr. There has been increasing use of aerial refueling to extend flight times in the latter years.

The publication rate (reference reports and papers) was approximately $6 / y r$ for the first $6 \mathrm{yr}$ and has increased to approximately $19 / \mathrm{yr}$ for the last $3 \mathrm{yr}$.

\section{Summary}

A 10-yr flight research program has been conducted at NASA Ames-Dryden with the F-15 airplane. More than 330 flights have been flown, and over 85 reports and papers have been published. The F-15 has been demonstrated to be a versatile and effective airplane for a wide variety of flight experiments. The results have been used to provide early insight into problems before new systems are committed to production. It has served as an effective way to transition technology into operational use. Results have been used to verify and validate some currentiy used test techniques, as well as to point out limitations and weaknesses in some areas. Flight test trajectory guidance techn1ques that have been developed have increased the quality of data for this and other flight research programs. The F-15 has served as a test-bed for proving advanced equipment for other flight vehicles and for carrying basic aerodynamic experiments into the true flight environment.

\section{Acknowledgment}

The $\mathrm{F}-15$ research program was sponsored by the NASA office of Aeronautics and Space Technology, High-Speed Aircraft Division, Jack Levine, Manager.

\section{References}

1Szalal, K.J., "Role of Research Aircraft in Technology Development," AIAA Paper 84-2473, Nov. 1984.

\section{Trajectory Guidance}

2Swann, M.R., Duke, E.L., Enevoldson, E.K., and Wolf, T.D., "Experience With Flight Test Trajectory Guidance," AIAA Paper 81-2504, Nov. 1981.

3walker, R.A. and Gupta, N.K., "Flight Test Trajectory Control Analysis," NASA CR-170395, 1983.

4Duke, E.L., Swann, M.R., Enevoldson, E.K., and Wolf, T.D., "Experience With Flight Test Trajectory Guidance," J. Guidance, Control, and Dynamics, vol. 6, no. 5, Sept.-Oct. 1983, pp. 393-398.

5walker, R.A., Gupta, N.K., Duke, E.L., and Patterson, B., "Developments in Flight Test Trajectory Control," AIAA Paper 84-0240, Jan. 1984. 
6Menon, P.K.A., Saberı, H.A., Walker, R.A., and Duke, E.L., "Flight Test Trajectory Controller Synthesis With Constrained Eigenstructure Assignment," American Control Conference Proc., vol. 3, June 1985, pp. 1181-1186.

7 Alag, G.S. and Duke, E.L., "Development of Control Laws for a Flight Test Maneuver Autopilot for an F-15 Aircraft," NASA TM-86736, 1985.

8Duke, E.L. and Antoniewicz, R.F., "Development and Validation of a General Purpose Linearization Program for Rigid Aircraft Models," NASA TM-86737, 1985.

${ }^{9} \mathrm{Alag}$, G.S. and Duke, E.L., "Development of a Flight Test Maneuver Autopilot for an F-15 Aircraft," NASA TM-86799, 1985.

Stability and Control, Handling Qualities, Buffet, and Tracking

10Sisk, T.R., "A Technique for the Assessment of Fighter Aircraft Precision Controllability," AIAA Paper 78-1364, Aug. 1978.

11Sisk, T.R. and Matheny, N.W., "Precision Controllability of the F-15 Airplane," NASA TM-72861, 1979.

12Lorincz, D.J. and Friend, E.L., "Water Tunnel Visualization of the Vortex Flows of the F-15," AIAA Paper 79-1649, Aug. 1979.

\section{0-Deg Transition Cone}

13 Dougherty, N.S., Jr. and F1sher, D.F., "Boundary Layer Transition on a 10-Degree Cone. Wind Tunnel/ Flight Data Correlation," AIAA Paper 80-0154, Jan. 1980.

${ }^{14}$ Saltzman, E.J. and Ayers, T.G., "A Review of Flight-to-Wind Tunnel Drag Correlation," AIAA Paper 81-2475, Nov. 1981.

15Dougherty, N.S., Ur. and Fisher, D.F., "BoundaryLayer Transition Correlation on a Slender Cone in Wind Tunnels and Flight for Indications of Flow Quality," NASA TM-84732, 1982.

16 Fisher, D.F. and Dougherty, N.S., Jr., "In-Flight Transition lleasurement on a $10^{\circ}$ Cone at Mach Numbers From 0.5 to 2.0," NASA TP-1971, 1982.

17Fisher, D.F. and Dougherty, N.S., Jr., "Flight and Wind-Tunnel Correlation of Boundary-Layer Transition on the AEDC Transition Cone," Ground/ Flight Test Techniques and Correlations, AGARD CP-339, Oct. 1982, pp. 5-1 to 5-25.

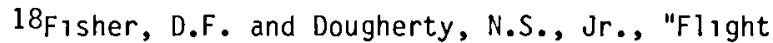
and Wind-Tunnel Correlation of Boundary-Layer Transition on the AEDC Transition Cone," NASA TII-84902, 1982.

\section{0-Deg Cone Separation}

19McRae, D.S., Peake, D.J., and Fisher, D.F., "A Computational and Experimental Study of High Reynolds Number Viscous/Inviscid Interaction About a Cone at Hrgh Angle of Attack," AIAA Paper 80-1422, July 1980.

20 Peake, D.J., Fisher, D.F., and McRae, D.S., "Flight Experiments With a Slender Cone at Angle of Attack," AIAA Paper 81-0337, Jan. 1981.

21Peake, D.J., Fisher, D.F., and McRae, D.S., "Flight, Wind Tunnel, and Numerical Experiments With a Slender Cone at Incidence," AIAA J., vol. 20, no. 10, Oct. 1982, pp. 1338-1345.

\section{Engine-Inlet Compatibility}

22Stevens, C.H., Spong, E.D., and Hammock, M.S., "F-15 Inlet/Engine Test Techniques and Distortion Methodologies Studies," NASA CR-144866, 1978.

${ }^{23}$ Stevens, C.H., Spong, E.D., Nugent, J., and Neumann, H.E., "Reynolds Number, Scale, and Frequency Content Effects on F-15 instantaneous Distortion," AIAA Paper 79-0104, Jan. 1979.

\section{Engine Calibrations}

24kurtenbach, F.J., "Comparison of Calculated and Altitude-Facility-Measured Thrust and Airflow of Two Prototype F100 Turbofan Englnes," NASA TP-1373, 1978.

25Biesıadny, T.J., Lee, D., and Rodriguez, J.R., "Airflow and Thrust Calibration of an F100 Engine, S/N P680059, at Selected Flight Conditions," NASA TP-1069, 1978.

26Bresiadny, T.J., Lee, D., and Rodriguez, J.R., "Altitude Calibration of an F100, S/N P680063, Turbofan Engine," NASA TP-1228, 1978.

27Kurtenbach, F.J., "Evaluation of a Simplified Gross Thrust Calculation Technique Using Two Prototype F100 Turbofan Engines in an Altitude Facility," NASA TP-1482, 1979.

\section{Inlet-Airframe Integration}

28 Webb, L.D., Whitmore, S.A., and Janssen, R.L., "Preliminary Flight and Wind Tunnel Comparisons of the Inlet/Airframe Interaction of the F-15 Airplane," AIAA Paper 79-0102, Jan. 1979.

29 Webb, L.D. and Nugent, J., "Results of the F-15 Propulsion Interactions Program," AIAA Paper 82-1041, June 1982.

30 Webb, L.D., Andriyich-Varda, D., and Whitmore, S.A., "Flight and Wind-Tunnel Comparisons of the Inlet/Airframe Interaction of the F-15 Airplane," NASA TP-2374, 1984. 


\section{Nozzle and Aft Engine Integration}

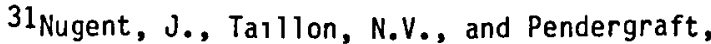
0.C., Jr., "Status of a Nozzle-Aurframe Study of a Highly Maneuverable Fighter," AIAA Paper 78-990, July 1978.

32plant, T.J., Nugent, J., and Davis, R.A., "Flight-Measured Effects of Boatta1l Angle and Mach Number on the Nozzle Afterbody Flow of a Twin-jet Fighter," AIAA Paper 80-0110, Jan. 1980.

33 Nugent, J., Plant, T.J., Davis, R.A., and Tallion, N.V., "Pressures Measured in Flight on the Aft Fuselage and External Nozzle of a Twin-Jet Fighter," NASA TP-2017, 1983.

34pendergraft, O.C., Jr. and Carson, G.T., Jr., "Fuselage and Nozzle Pressure Distributions of a 1/12-Scale F-15 Propulsion Model at Transonic Speeds," NASA TP-2333, 1984.

35Pendergraft, 0.C., Jr. and Nugent, J., "Results of a Wind Tunnel/Flight Test Program To Compare Afterbody/Nozzle Pressures on a $1 / 12$ Scale Model and an F-15 Aircraft," SAE Paper 84-1543, Oct. 1984.

36Nugent, J. and Pendergraft, 0.C., Jr., "Comparison of Wind Tunnel and Flight Test Afterbody and Nozzle Pressures for a Twin-Jet Fighter Aircraft at Transonic Speeds," NASA TP-2588, 1986.

\section{In-Flight Thrust}

37Kurtenbach, F.J. and Burcham, F.W., Jr., "Flight Evaluation of a Simplified Gross Thrust Calculation Technique Using an F100 Turbofan Engrne in an F-15 Arrplane," NASA TP-1782, 1981.

\section{Shuttle Tiles}

38Meyer, R.R., Jr., Jarvis, C.R., and Barneburg, Jack, "In-Flight Aerodynamic Load Testing of the Shuttle Thermal Protection System," AIAA Paper 81-2468, Nov. 1981.

\section{Engine-Inlet Static Pressure}

${ }^{39}$ Foote, C.H. and Jaekel, R.J., "Flight Evaluation of an Engine Static Pressure Noseprobe in an F-15 Airplane," NASA CR-163109, 1981.

40Hughes, D.L., Myers, L.P., and Mackall, K.G., "Effects of Inlet Distortion on a Static Pressure Probe llounted on the Engine Hub in an F-15 Airplane," Digital Electronic Engine Control (DEEC) Flight Evaluation in an F-15 Airplane, NASA CP-2298, 1984, pp. 73-89.

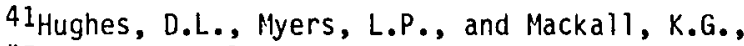
"Effects of Inlet Distortion on a Static Pressure Probe Mounted on the Englne Hub in an F-15 Airplane," NASA TP-2411, 1985.

DEEC

42Barrett, W.J., Rembold, J.P., Burcham, F.W., Jr., and Myers, L.P., "Flight Test of a Full
Authority Digital Electronic Engine Control System in an F-15 Aircraft," AIAA Paper 81-1501, July 1981.

43Burcham, F.W., Jr., Myers, L.P., Nugent, J., Lasagna, P., and Webb, L.D., "Recent Propulsion System Flight Tests at NASA Dryden Flight Research Center," AIAA Paper 81-2438, Nov. 1981.

44Myers, L., Mackal 1, K., Burcham, F.W., Jr., and Waiter, W., "Flight Test Results of a Digital Electronic Engine Control System in an F-15 Airplane," AIAA Paper 82-1080, June 1982.

45Barrett, W.J., Rembold, J.P., Burcham, F.W., Jr., and Myers, L.P., "Digital Electronic Engine Control System - F-15 Filight Test," J. Aircraft, vol. 20, no. 2, Feb. 1983, pp. 134-141.

46Licata, S.J. and Burcham, F.W., Jr., "Airstart Performance of a Digital Electronic Engine Control System in an F-15 Airplane," NASA TM-84908, 1983.

47Kock, B.M., "Digital Electronic Engine Control F-15 Overview," Digital Electronic Engine Control (DEEC) Flight Evaluation in an F-15 Airplane, NASA CP-2298, 1984, pp. 1-14.

48putnam, T.W., "Digital Electronic Engine Control History," Digital Electronic Engine Control (DEEC) Flight Evaluation in an F-15 A1rplane, NASA CP-2298, 1984, pp. 15-31.

49Myers, L.P., "F-15 Digital Electronic Engine Control System Description," Digital Electronic Engine Control (DEEC) Flight Evaluation in an F-15 Airplane, NASA CP-2298, 1984, pp. 33-53.

50werner, R.A., Willoh, R.G., Jr., and Abdelwahab, M., "NASA Lewis F100 Engine Testing," Digital Electronic Engine Control (DEEC) Flight Evaluation in an F-15 Airplane, NASA CP-2298, 1984, pp. 55-71.

51Myers, L.P., "Flight Testing the Digital Electronic Engine Control in the F-15 Airplane," Digital Electronic Engine Control (DEEC) Flight Evaluation in an F-15 Airplane, NASA CP-2298, 1984, pp. 91-105.

52Baer-Riedhart, J.L., "Digital Electronic Engine Control Fauit Detection and Accommodation Flight Evaluation," Digital Electronic Engine Control (DEEC) Flight Evaluation in an F-15 Airplane, NASA CP-2298, 1984, pp. 107-126.

53Walsh, K.R. and Burcham, F.W., Jr., "Flight Evaluation of a Hydromechanical Backup Control for the Digital Electronic Engine Control System in an F100 Engine," Digital Electronic Engine Control (DEEC) Flight Evaluation in an F-15 Arrplane, NASA CP-2298, 1984, pp. 141-155.

54Johnson, J.B., "Backup Control Airstart Performance on a Digital Electronic Engine ControlEquipped F100 Engine," Digital Electronic Engrne Control (DEEC) Flight Evaluation in an F-15 Airplane, NASA CP-2298, 1984, pp. 157-170. 


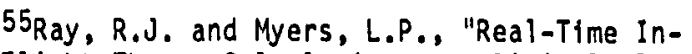
Flight Thrust Calculation on a Digital Electronic Engine Control-Equipped F100 Engine in an F-15 Airplane," Digital Electronic Engine Control (DEEC) Flight Evaluation in an F-15 Arrplane, NASA CP-2298, 1984, pp. 215-230.

56Putnam, T.W., Burcham, F.W., Jr., and Kock, B.M., "Flight Testing the Digital Electronic Engrne Control (DEEC) - A Unique Management Experience," 14th Annual SFTE Symposium Proc., 1983, pp. 2.2-1 to $2.2-6$.

57Myers, L.P. and Burcham, F.W., Jr., "Comparison of Results Obtained From Flight Tests and Simulated Tests of a Digital Electronic Engine Control System in an F-15 Airplane," NASA TM-84903, 1983.

58 Burcham, F.W., Jr., Myers, L.P., and Walsh, K.R., "Flight Evaluation Results for a Digital Electronic Engine Control in an F-15 Airplane," AIAA Paper 83-2703, Nov. 1983.

59Johnson, J.B. and Nelson, J., "Flight Evaluation of the DEEC Secondary Engine Control A1r-Start Capability," NASA TM-84910, 1983.

60Burcham, F.W., Jr., Myers, L.P., and Zeller, J.R., "Flight Evaluation of Modifications to a Digital Electronic Engine Control System in an F-15 Airplane," NASA TM-83088, 1983.

6lBurcham, F.W., Jr., "A1rstart Performance of a Digital Electronic Engine Control System on an Fl00 Engine," Digital Electronic Engine Control (DEEC) Flight Evaluation in an F-15 Airplane, NASA CP-2298, 1984, pp. 127-139.

62Burcham, F.W., Jr., and Par, G.D., "Augmentor Transient Capability of an F100 Engine Equipped With a Digital Electronic Engine Control," Digital Electronic Engine Control (DEEC) Flight Evaluation in an F-15 Airplane, NASA CP-2298, 1984, pp. 171-199.

63Burcham, F.W., Jr. and Zeller, J.R., "Invest1gation of a Nozzle Instability on an F100 Engine Equipped With a Digital Electronic Engine Control," Digital Electronic Engine Control (DEEC) Flight Evaluation in an F-15 Airplane, NASA CP-2298, 1984, pp. 201-214.

64Ray, R.J., "In-Flight Thrust Determination on a Real-Time Basis," M.S. Thesis, California Polytechn1c Univ., San Lu1s 0bispo, Apr. 1984.

650igital Electronic Engrne Control (DEEC) Flight Evaluation in an F-15 Airplane, NASA CP-2298, 1984.

66 Myers, L.P., Baer-Riedhart, J.L., and Maxwell, M.D., "Fault Detection and Accommodation Testing on an F100 Enyine in an F-15 Airplane," NASA TM-86735, 1985.

67Burcham, F.W., Myers, L.P., and Walsh, K.R., "Flight Evaluation of a Digital Electronic Engine Control in an F-15 Airplane," J. Aircraft, vol. 22, no. 12, Dec. 1985, pp. 1072-1078.

\section{F100 EMD}

68Myers, L.P., and Burcham, F.W., Jr., "Prel1minary Flight Test Results of the F100 EMD Engine in an F-15 Airplane," NASA TM-85902, 1984.

${ }^{69}$ Cho, T.K. and Burcham, F.W., Jr., "Prelıminary Flight Evaluation of F100 Engine Model Derivative Airstart Capability in an F-15 Airplane," NASA TM-86031, 1984.

${ }^{70}$ Crawford, D.B. and Burcham, F.W., Jr., "Effect of Control Logic Modifications on Airstart Performance of F100 Engine Model Derivative Engines in an F-15 Airplane," NASA TM-85900, 1984.

71Walton, J.T. and Burcham, F.W., Jr., "Augmentor Performance of an F100 Engine Model Derivative Engine in an F-15 Airplane," NASA TM-86745, 1986.

HIDEC

72Burcham, F.W., Jr., "Propulsion-Flight Control Integration Technology," Active Controls in Aircraft Design, AGARD AG-234, Nov. 1978, pp. 7-1 to 7-9.

73Carlin, C.M. and Hastings, W.J., "Propulsion/ Flight Control Integration Technology (PROFIT) Design Analysis Status," NASA CR-144875, 1978.

${ }^{74}$ Carlin, C.M. and Hastings, W.J., "Propulsion/ Flight Control Integration Technology (PROFIT) Software System Definition," NASA CR-144876, 1979.

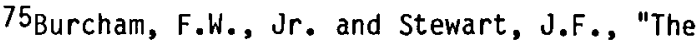
Development Process for Integrated PropulsionFlight Controls," Tactical Aircraft Research and Technology, NASA CP-2162, Part 1, 1980.

76 Yonke, W.A., "Integrated Flight/Propulsion Control: HIDEC Modes," MCAIR 84-011, MCDonnell Douglas Corp., 1984.

77Burcham, F.W., Jr. and Haerıng, E.A., Jr., "Highly Integrated Digital Engine Control System on an F-15 Airplane," NASA TM-86040, 1984.

78Myers, L.P. and Burcham, F.W., Jr., "Propulsion Control Experience Used in the Highly Integrated Digital Electronic Control (HIDEC) Program," NASA TM-85914, 1984.

79 Baer-Riedhart, J.L. and Landy, R.J., "Highly Integrated Digital Electronic Control - Digital Flight Control, Aircraft Model Identification and Adaptive Engine Control," AIAA Paper 85-1877, Aug. 1985.

80Haerıng, E.A., Jr. and Burcham, F W., Jr., "Minimum Time and Fuel Firght Profiles for an F-15 Alrplane With a Highly Integrated Digital Electronic Control System," NASA TM-86042, 1984.

81 Burcham, F.W., Jr., Myers, L.P., and Ray, R.J., "Predicted Performance Benefits of an Adaptive Digital Engine Control System on an F-15 Airplane," NASA TM-85916, 1985. 
82"Digital Electronic Engine Controls Examined," Aerosp. Eng., vol. 5, no. 2, Feb. 1985, pp. 34-38.

830 gborn, S., "State Variable Dynamic Model of a PW1128 Engine With a DEEC Control," P\&W FR-18761A, Pratt and Whitney, 1985.

${ }^{84}$ Yonke, W.A., Terre11, L.A., and Myers, L.P., "Integrated Flight/Propulsion Control: Adaptive Engine Control System Mode," AIAA Paper 85-1425, July 1985.

35Putnam, T.W., Burcham, F.W., Jr., Andries, M.G., and Kelly, J.B., "Performance Improvements of a
Highly Integrated Digital Electronic Control Sys tem for an F-15 Airplane," NASA TM-86748, 1985.

86 Andries, M.G. and Terrell, L.A., "Highly Integrated Digital Electronic Control HIDEC Sea Level Test Report for Engine P085-11," P\&W FR-19248, Pratt and Whitney, 1986.

High-Altitude Partial Pressure Protective System

87Ashworth, G.R., Putnam, T.W., Dana, W.J., Enevoldson, F.K., and Winter, W.R., "Flight Test Evaluation of an RAF High-Altitude Partial Pressure Protective Assembly," NASA TM-72864, 1979.

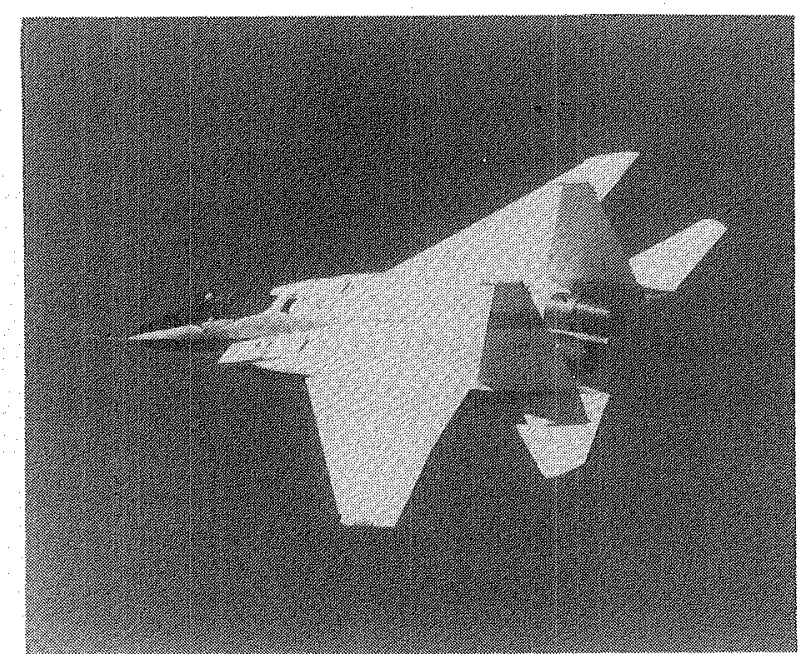

ECN 9325

Fig. 1 F-15 airplane in flight.

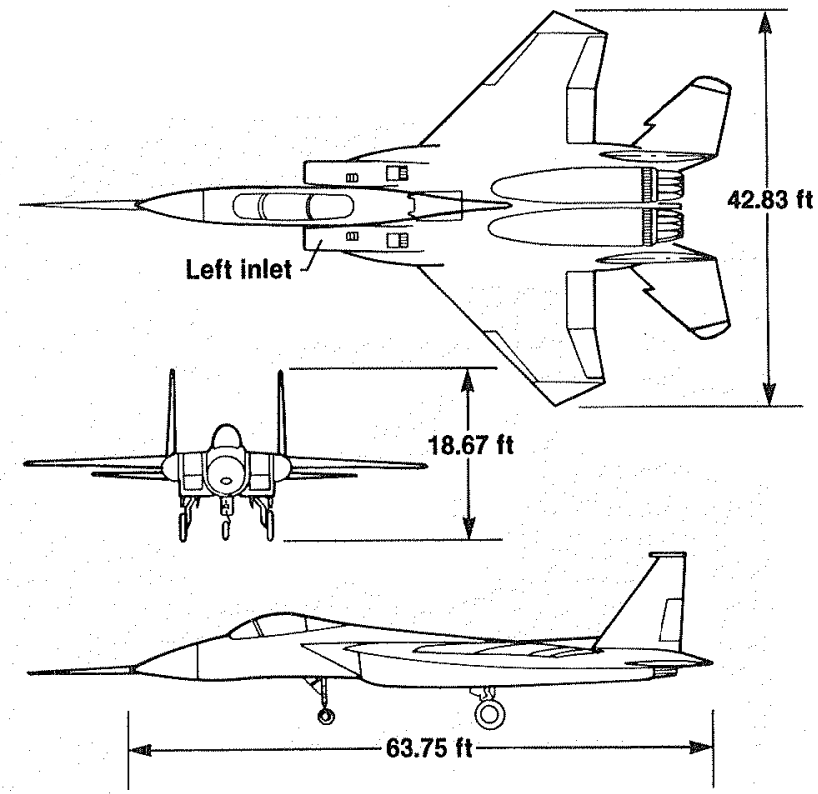

Fig. 2 Three-view of test airplane.

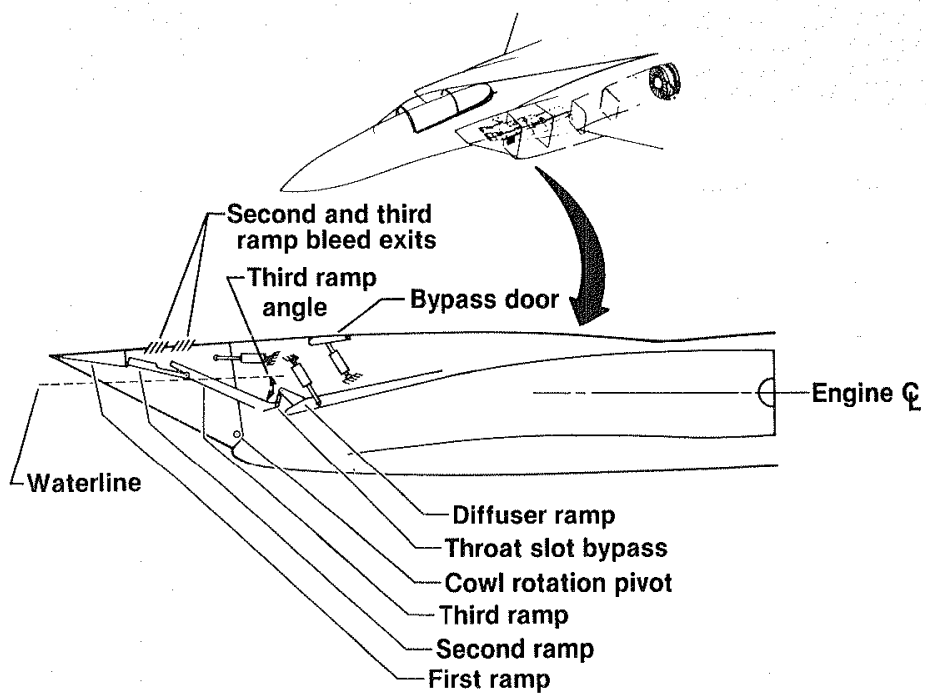

Fig. 3 F-15 inlet. 


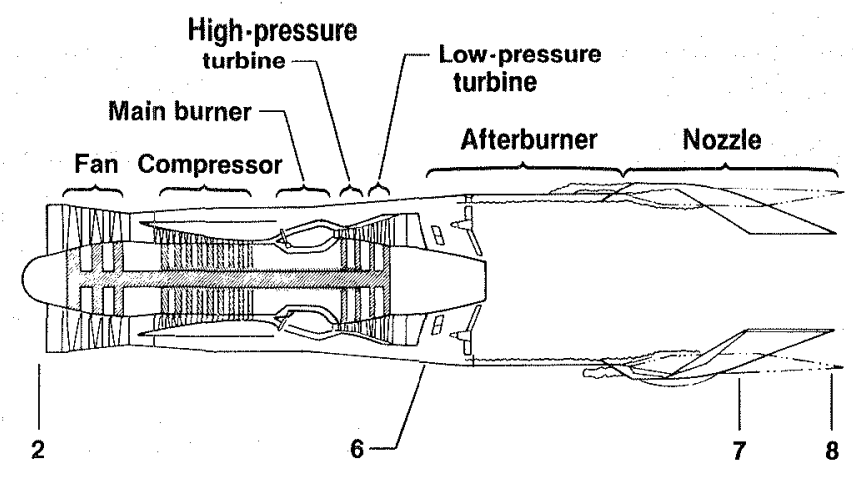

Fig. 4 F100 engine and stations.

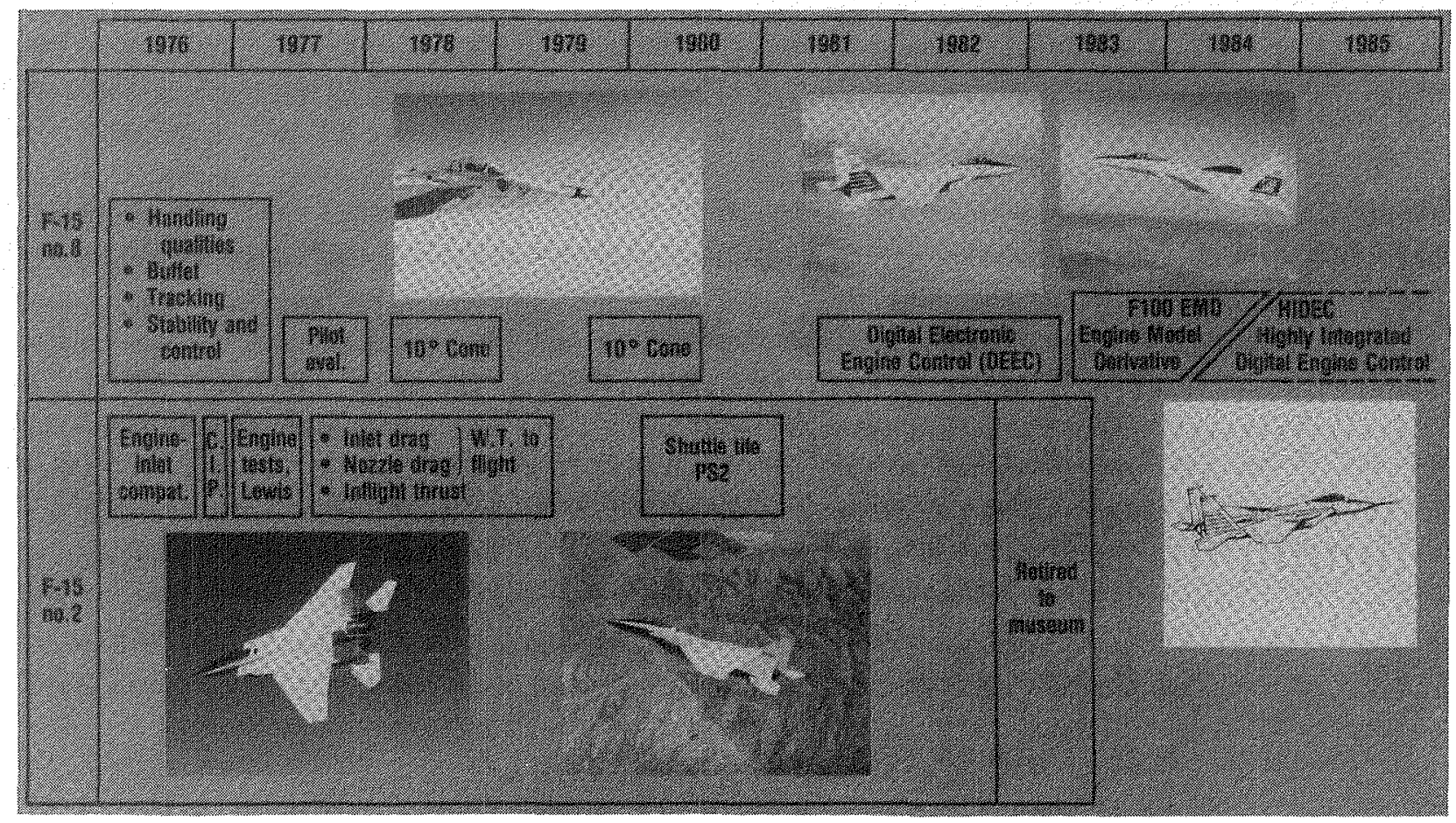

AD84-1401

Fig. 5 Summary of major F-15 flight research projects. 


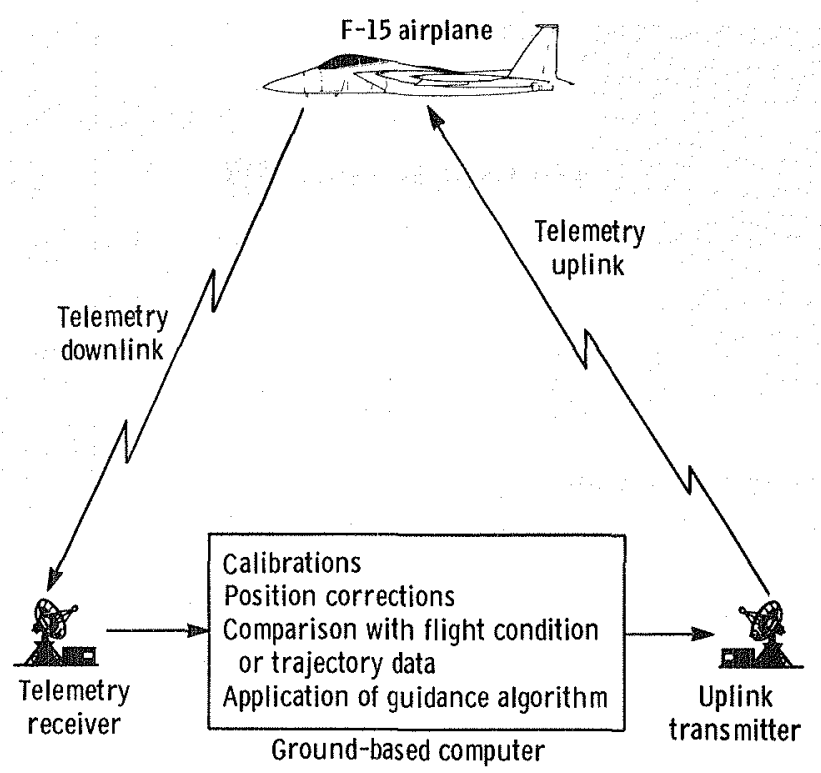

(a) Schematic view of flight test trajectory guidance system.

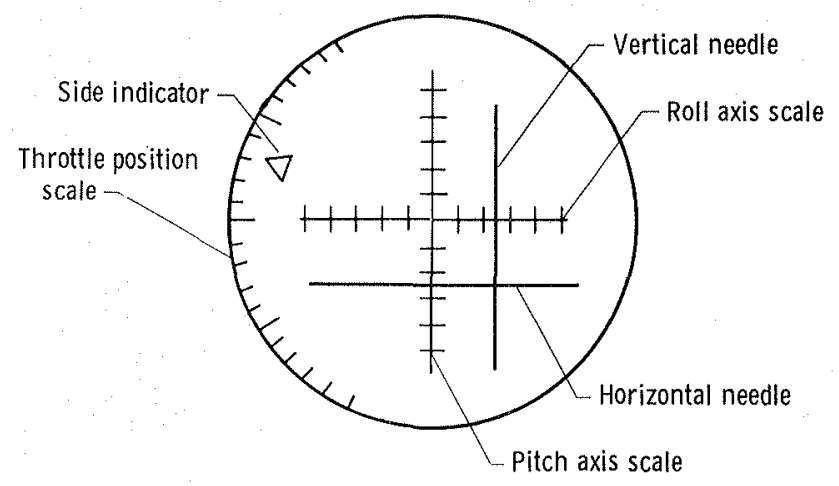

(b) Generic pilot display device.

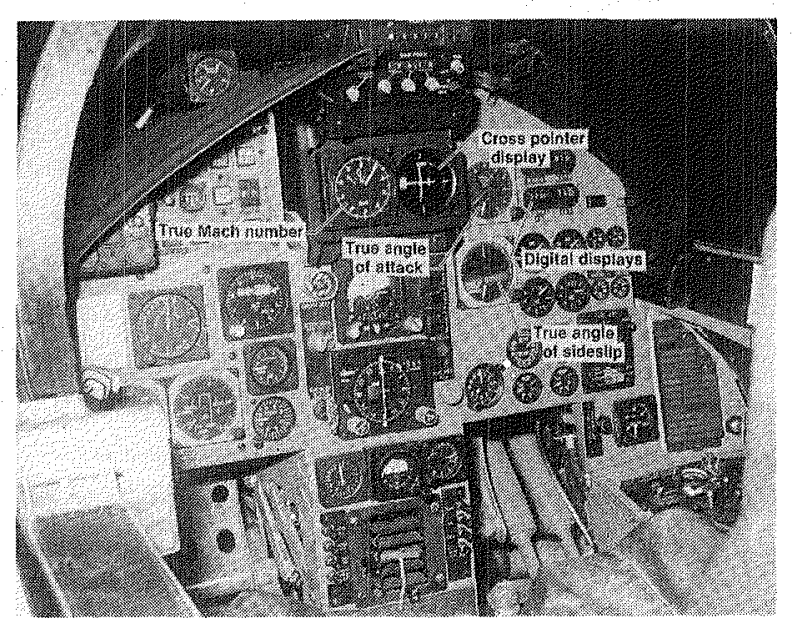

E 35039

(c) F-15 cockpit showing cockpit uplink displays.

Fig. 6 Flight test trajectory guidance system used in F-15 airplane. 


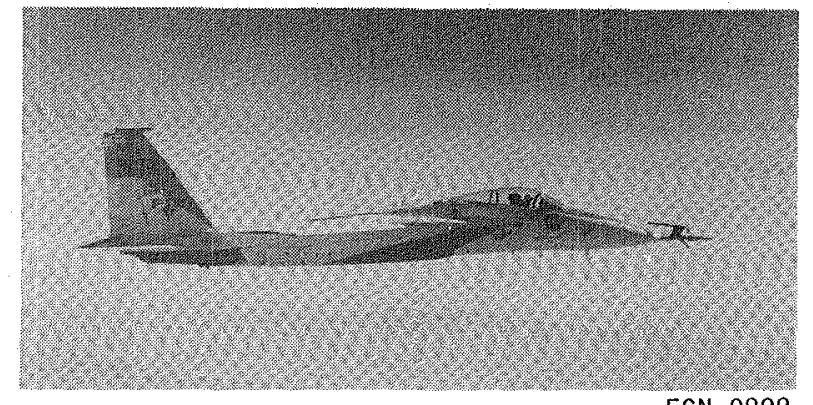

ECN 9808

(a) F-15 airplane with 10-deg cone installed.

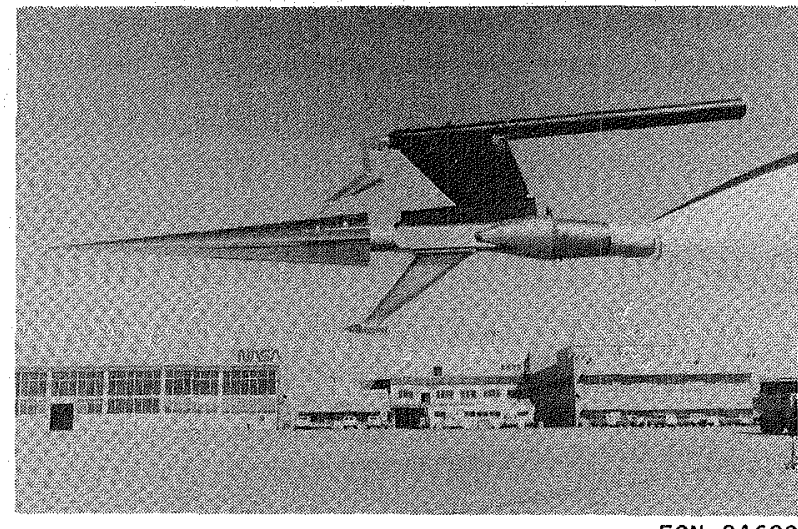

ECN 34629

(b) Closeup of 10-deg cone.

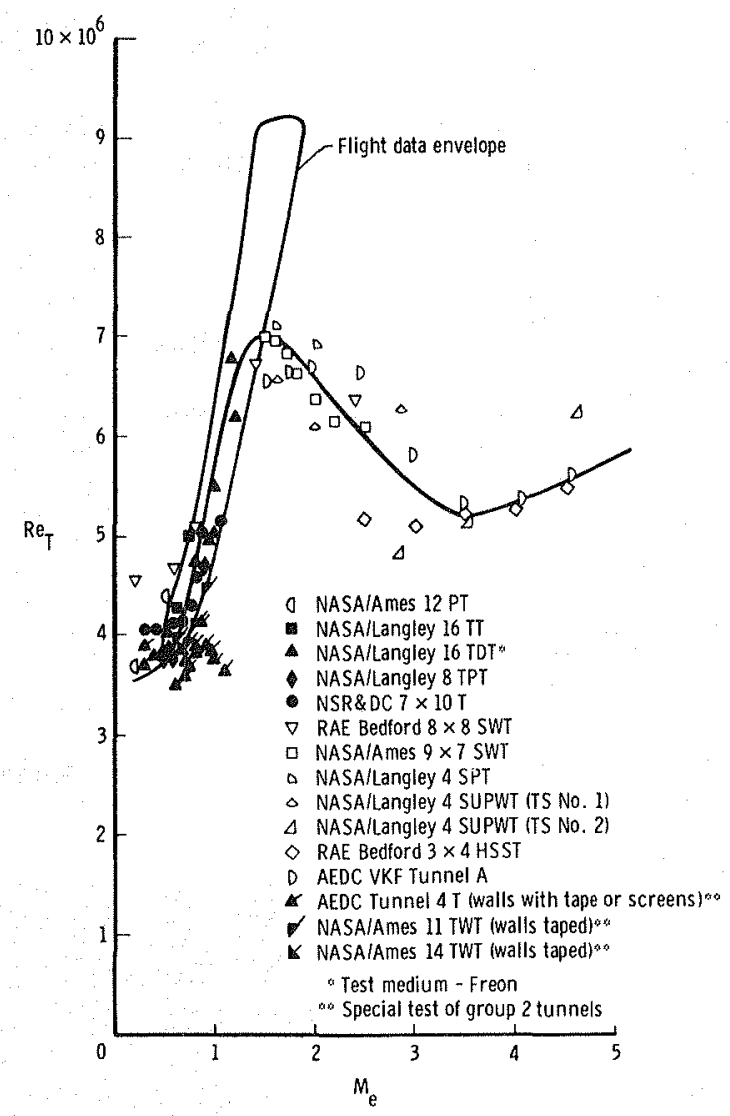

(d) Comparison of transition Reynolds number with Mach number for flight and lower noise wind tunnels, $R e=3.0 \times 106 / \mathrm{ft}$ (from Ref. 18). (c) Comparison of disturbance levels measured in wind tunnels with those measured in flight.
Conditions Zero incidence

$u_{\infty} / v_{\infty} \approx 3.0 \times 10^{6}$

Data from

higher noise

$\sqrt{\frac{\bar{p}_{s}^{\prime 2}}{q_{e}}} \times 100$, percent

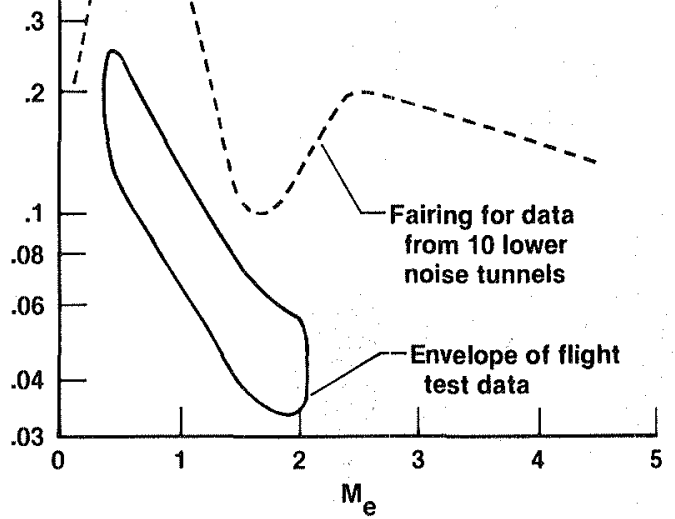

Fig. 7 Summary of results from 10-deg transition cone experiment. 


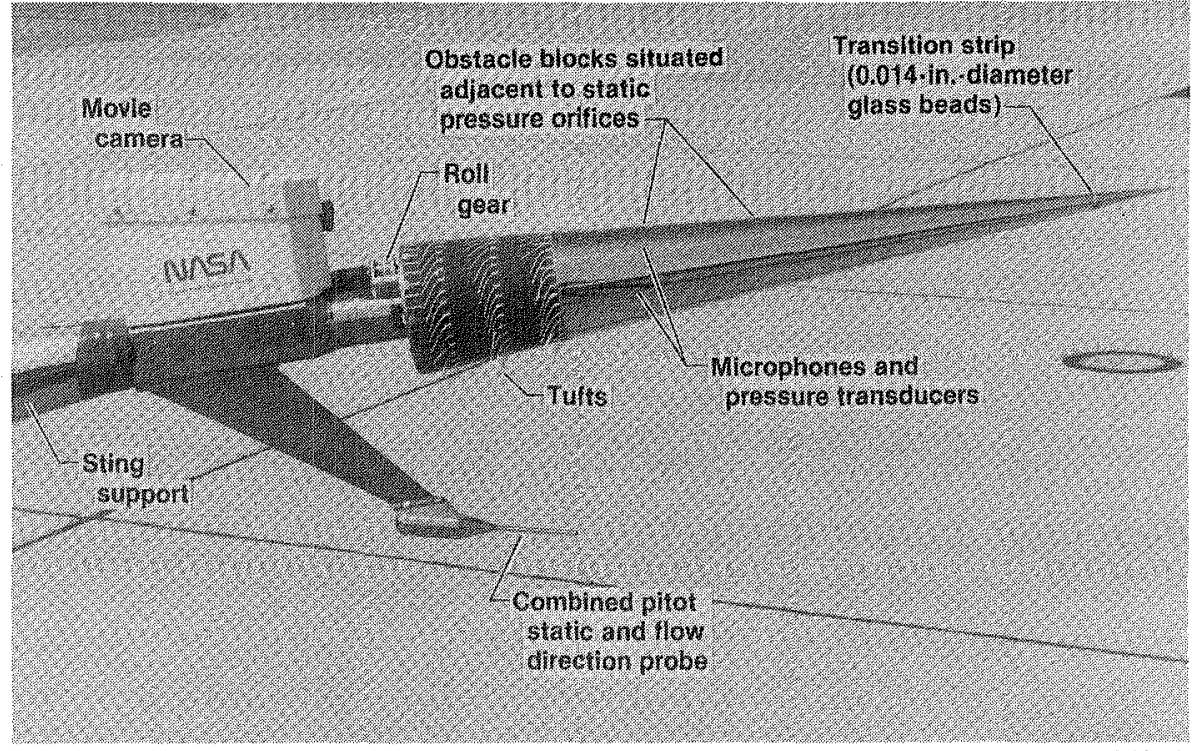

E 37308

(a) 10-deg cone at 11-deg incidence.

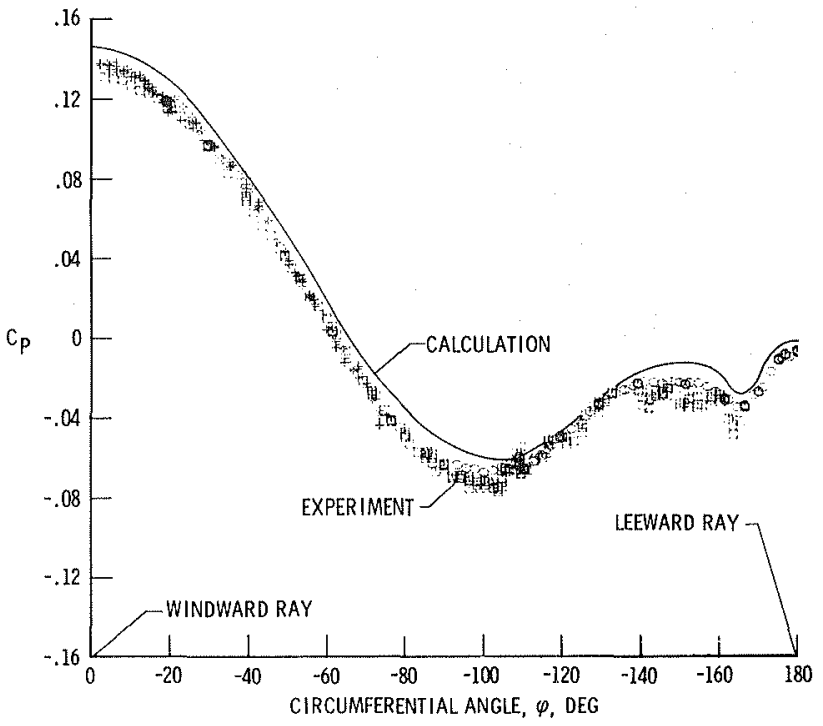

(b) Flight results, $R e=4.0 \times 106 / \mathrm{ft}$.
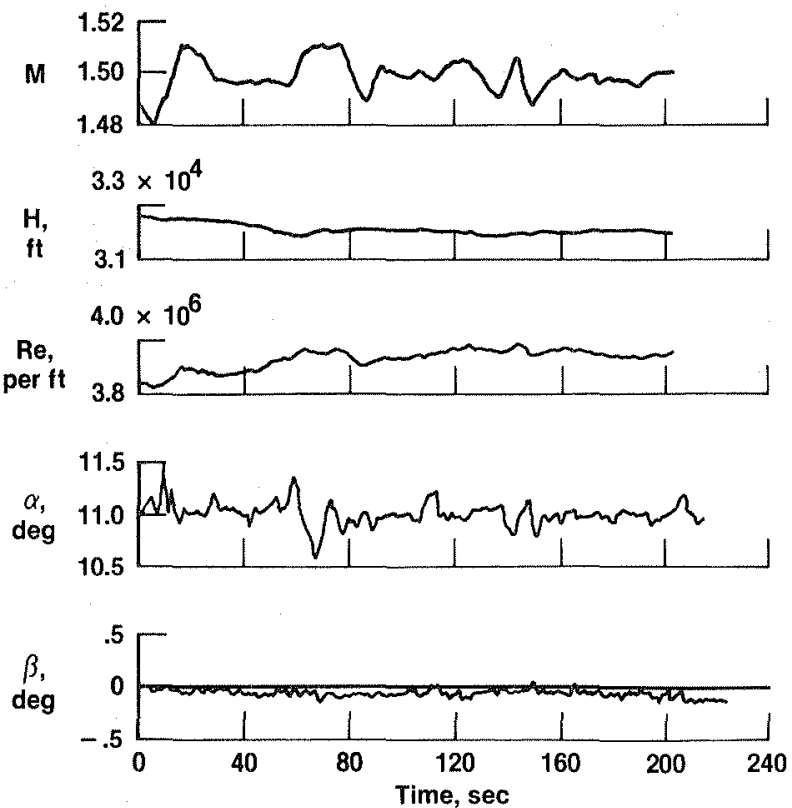

(c) Time history of typical $F-15$ cone experiment maneuver.

Fig. 8 10-deg cone separation experiment. 


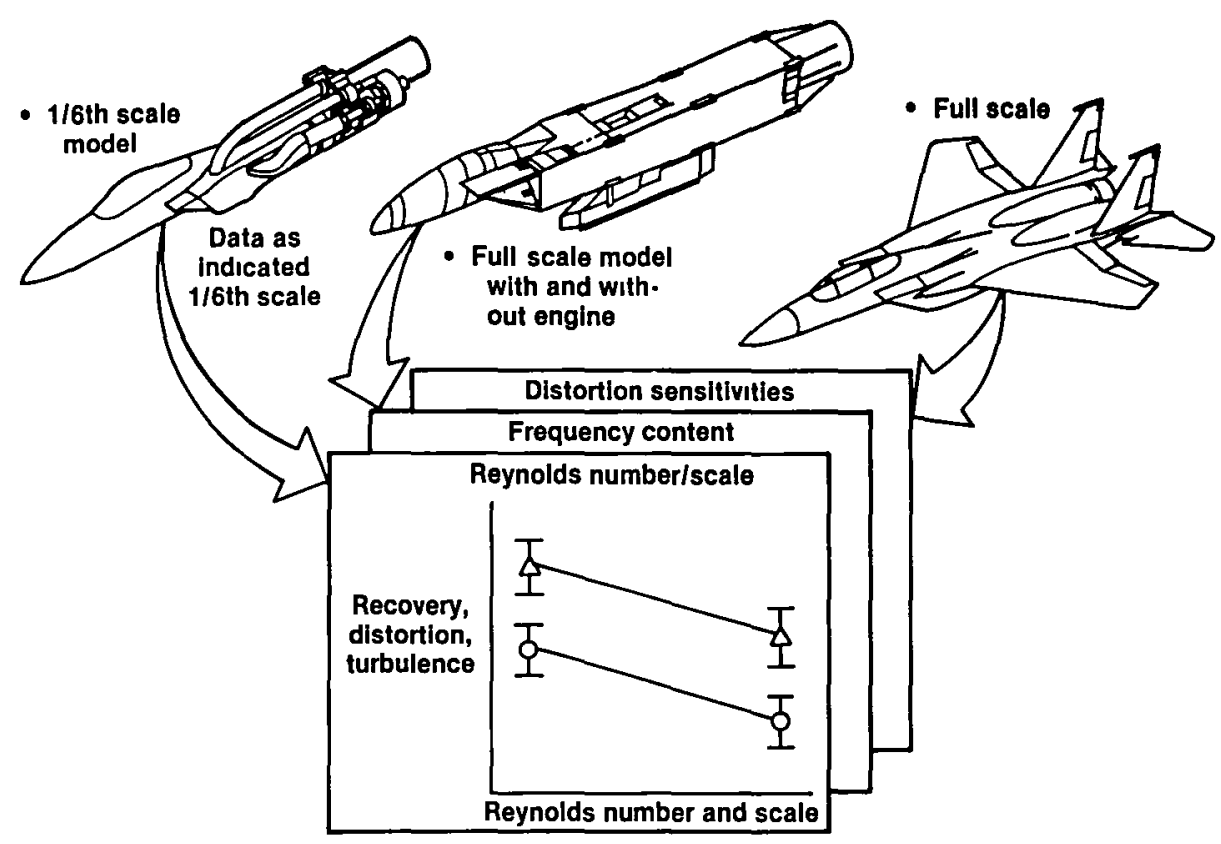

(a) One-sixth scale wind tunnel, full-scale wind tunnel, and flight data sources.

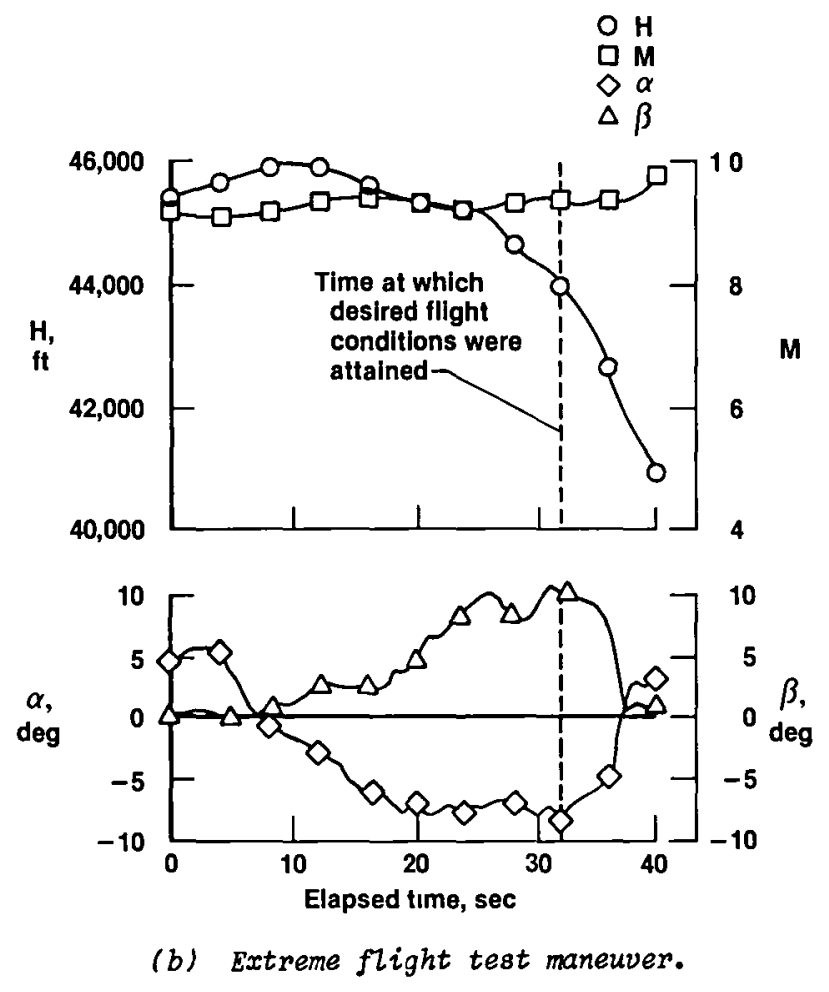

Fig. 9 Engrne-inlet compatibulity research project. 

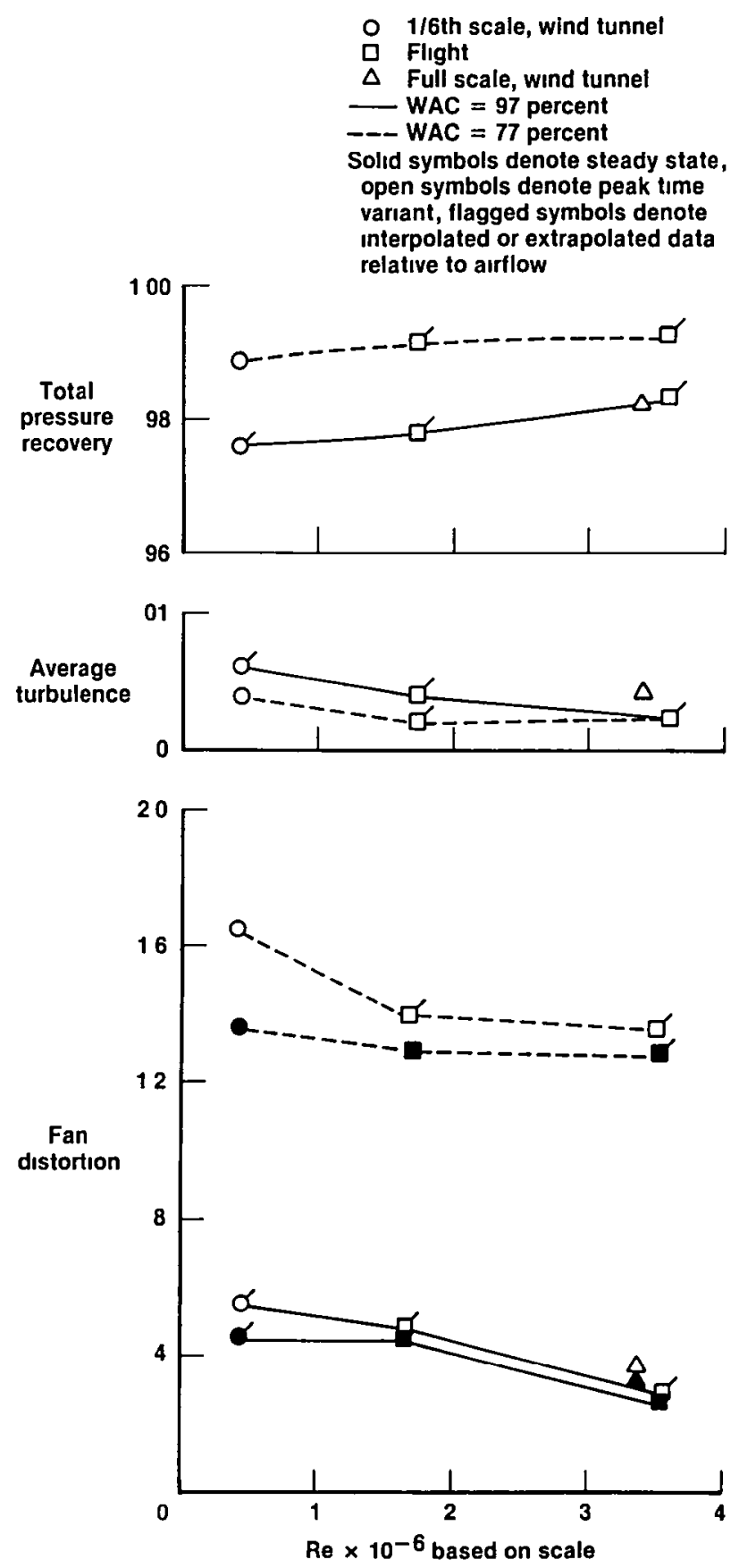

(c) Effect of Reynolds number and scale on total pressure recovery, turbulence, and fan distortion, $M=0.6, \alpha=4 \mathrm{deg}$, and $\beta=0 \mathrm{deg}$.

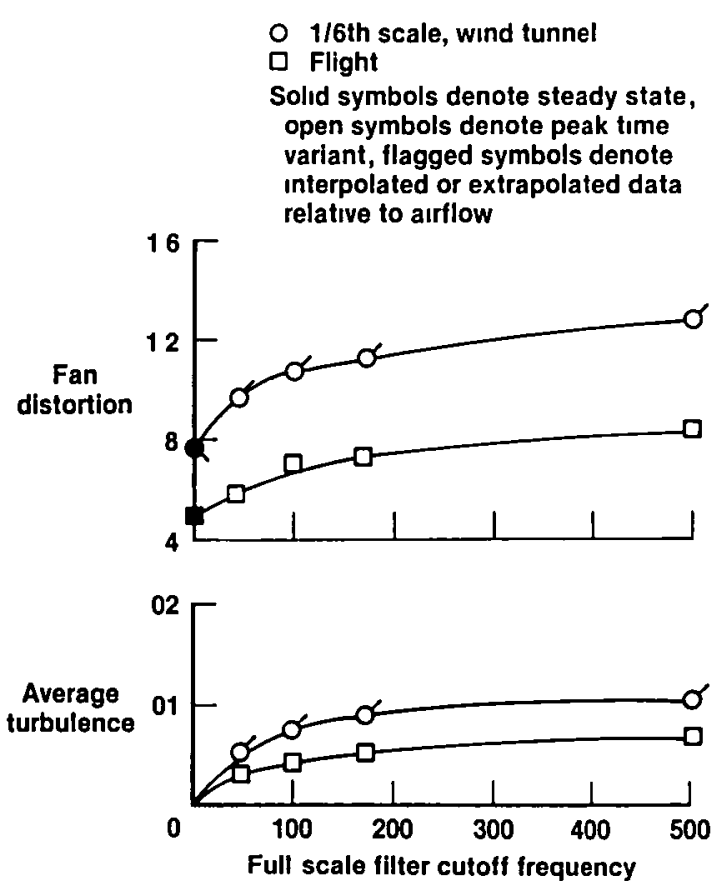

(d) Effect of fitter cutoff on fan distortron and turbulence, $M=1.8, \alpha=-2 \mathrm{deg}$, $\beta=0 \mathrm{deg}$, and $W A C=80.7$ percent.

Fig. $g$ concluded. 


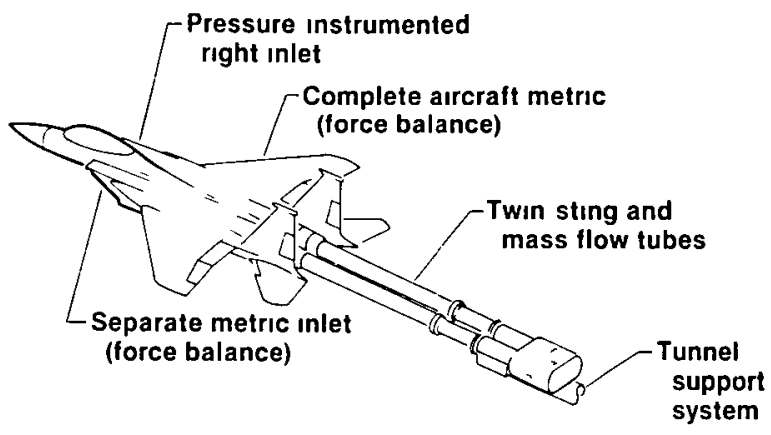

(a) Inlet model twrn force balance sting system.

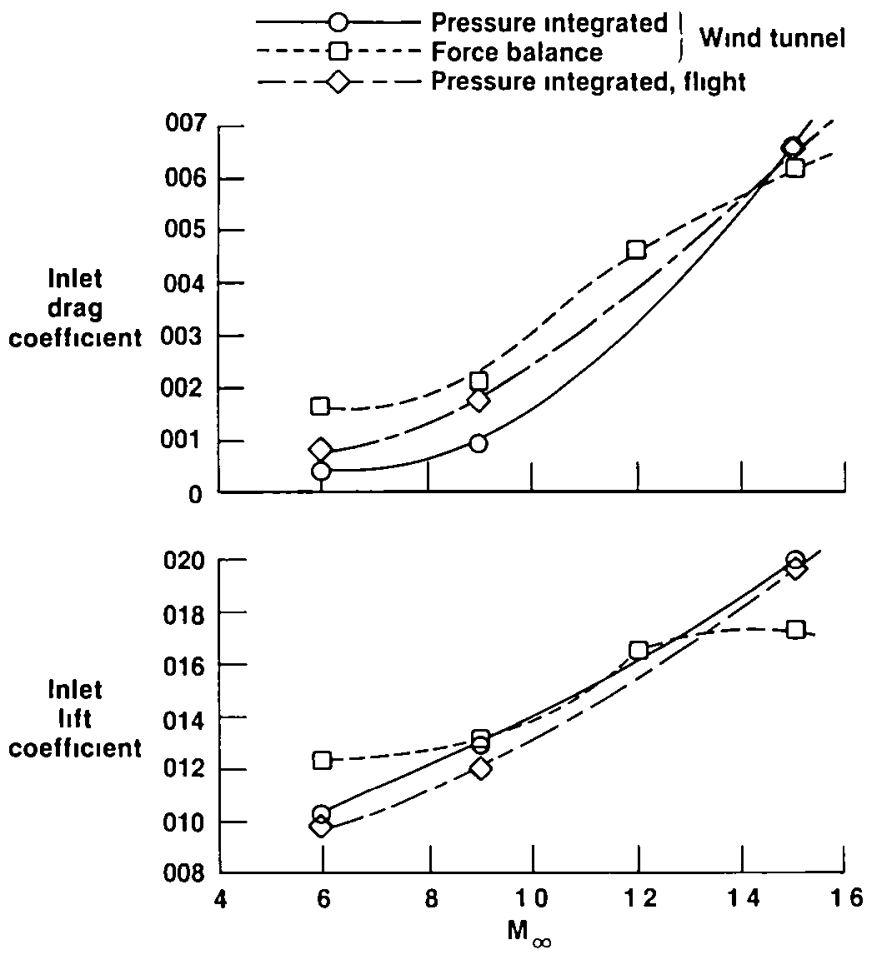

(b) Vamation of inlet lift and drag with Mach number, $\alpha=5$ deg.

Fig. 10 Inlet-airframe integration research project. 


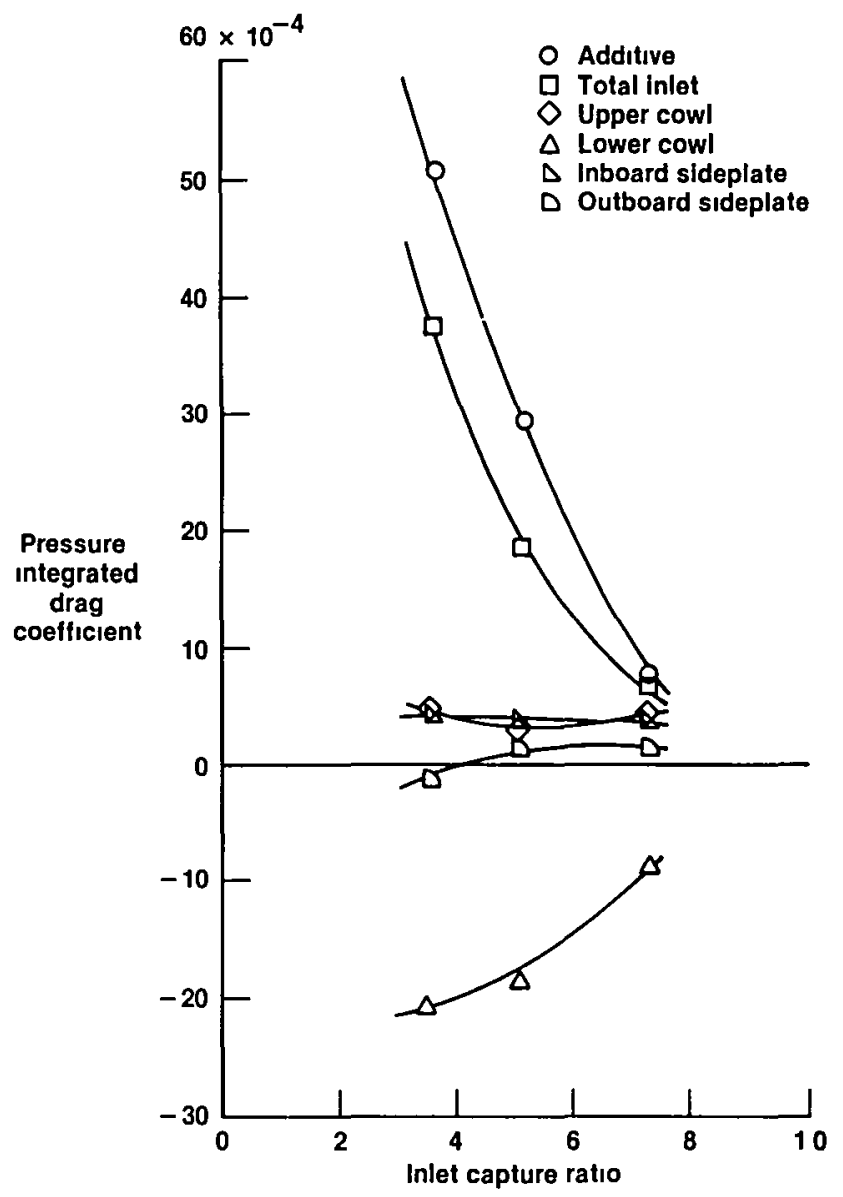

(c) Typrcal pressure integrated inlet drag components from $F-15$ flight data.

Fig. 10 Concluded. 


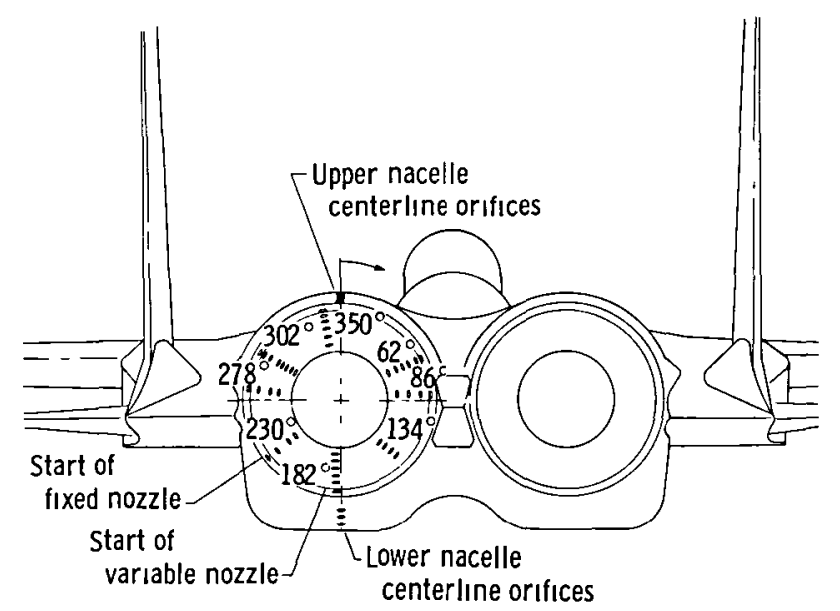

(a) Afterbody surface pressure instrumentation.
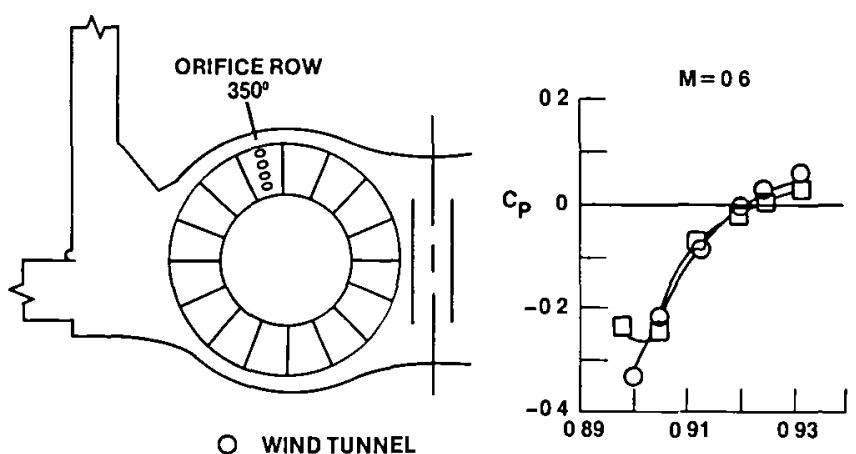

O WIND TUNNEL
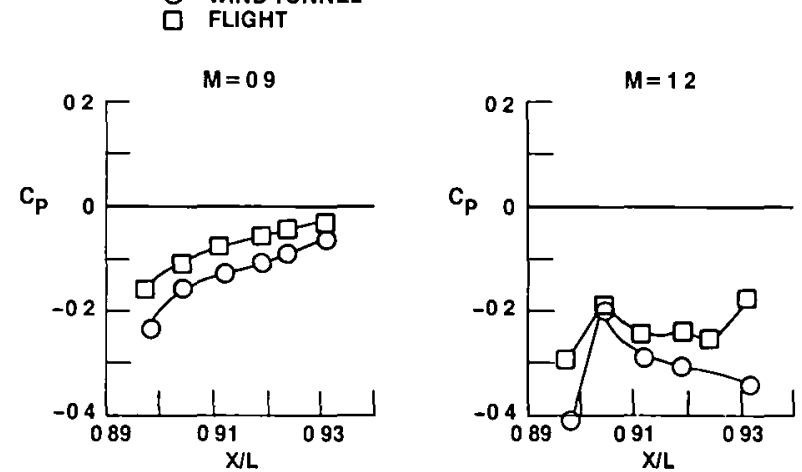

(b) Nozzle surface pressure coeffictent.

Fig. 11 Nozzle and aft engine integration research project. 


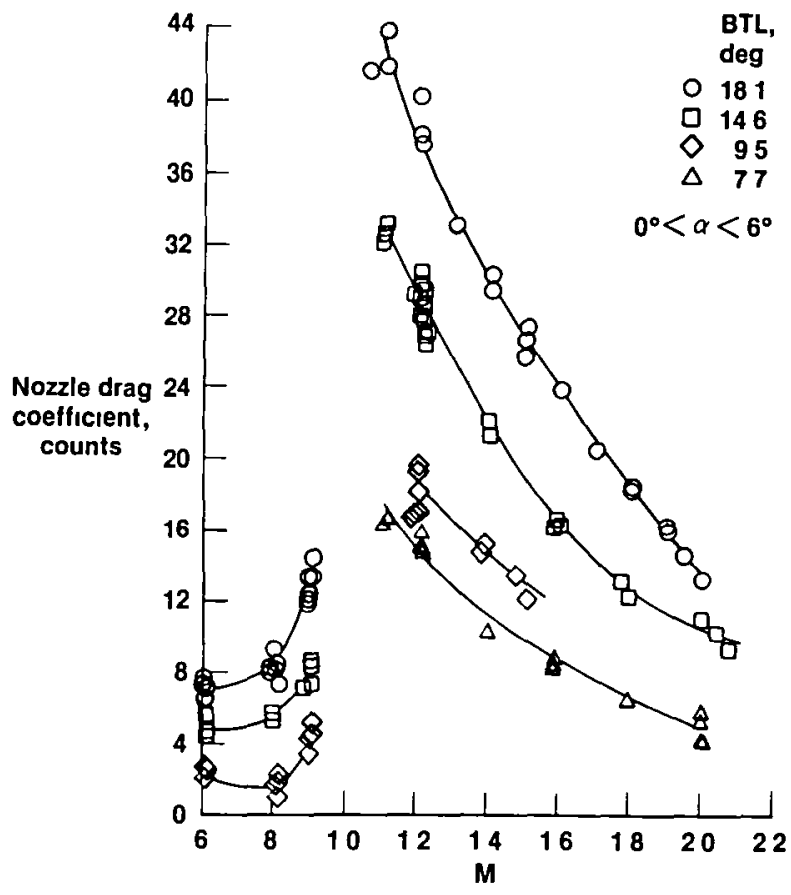

(c) Flight nozzle drag as a function of Mach number.

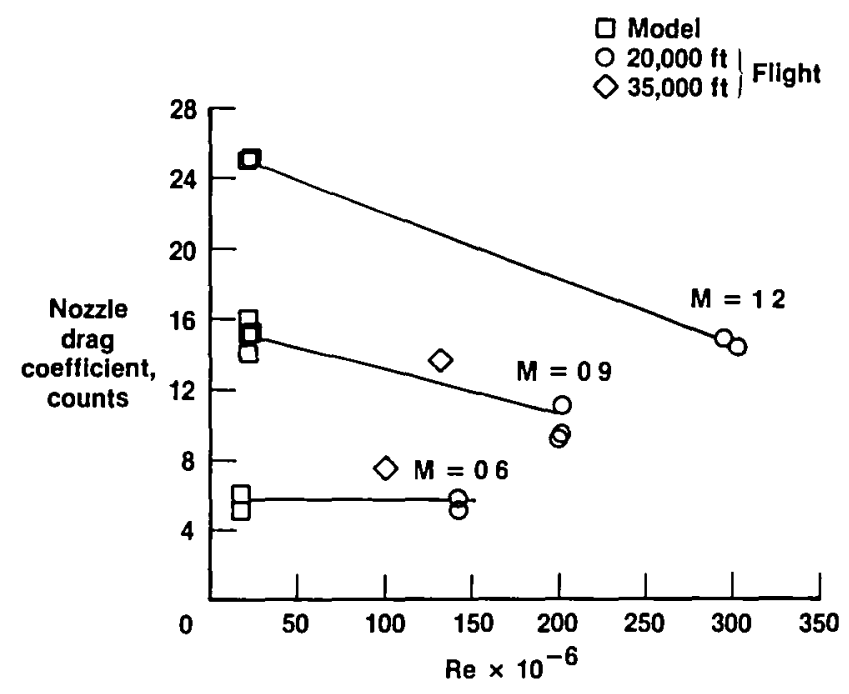

(d) Nozzle drag as a function of Reynolds number.

Fig. 11 Concluded. 


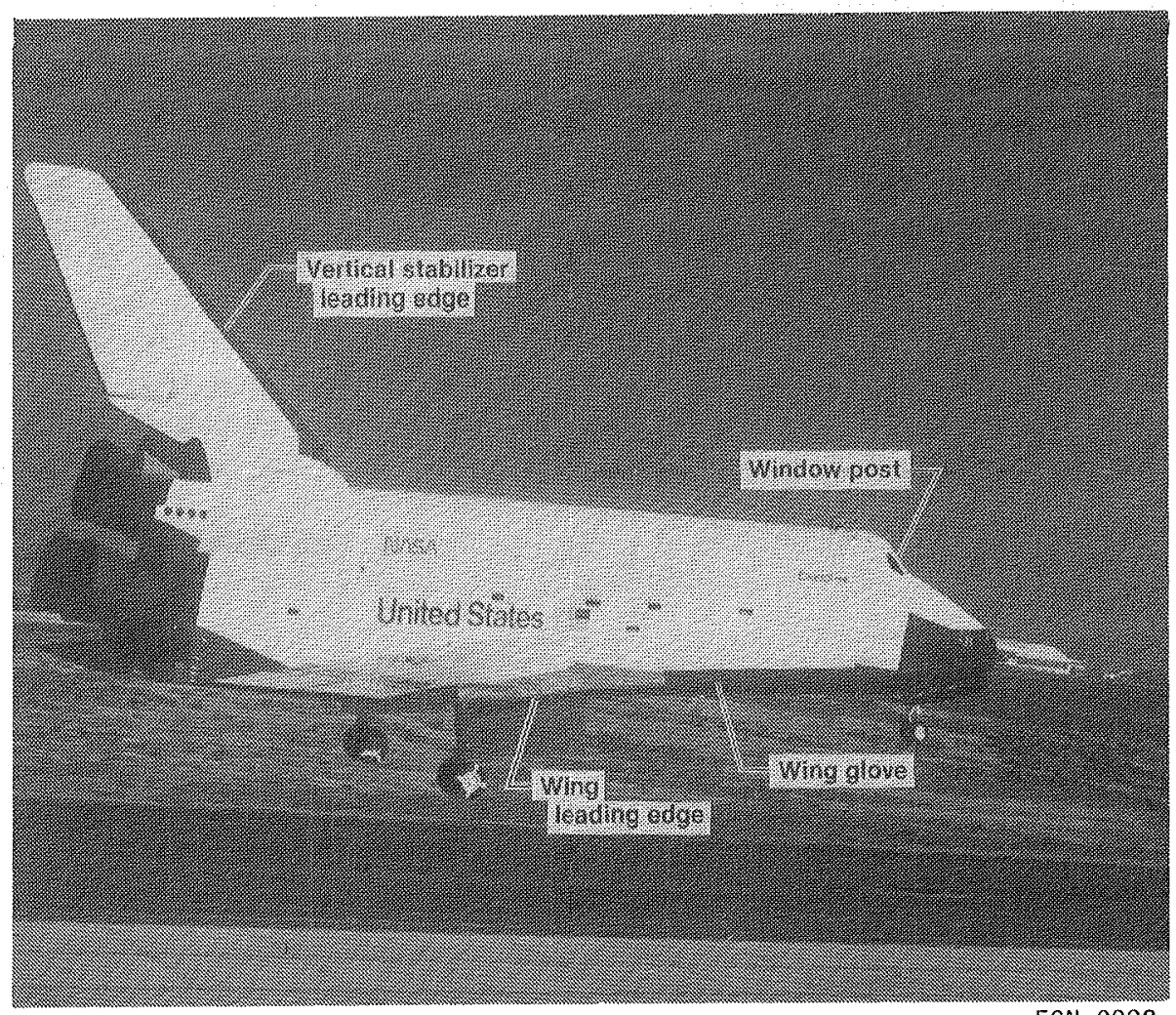

(a) Shuttie thermal protection system areas tested.

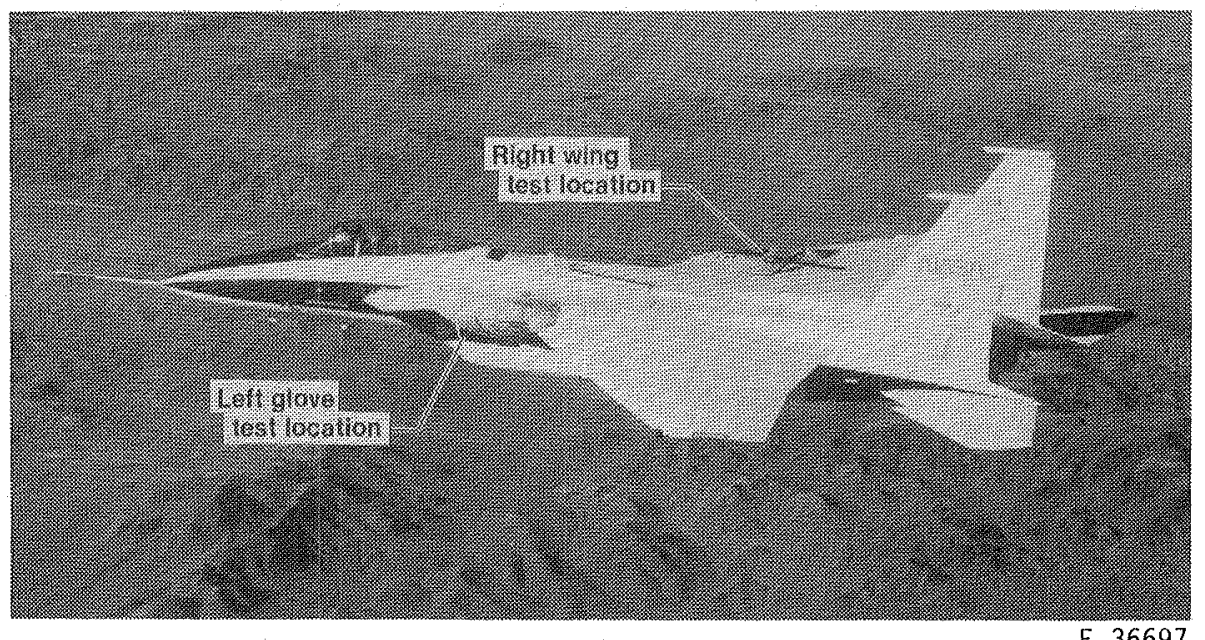

E 36697

(b) Airplane with test articles mounted in right wing and left glove Zocations.

Fig. 12 Space shuttle thermal protection system evaluation on F-15A-2 airplane. 


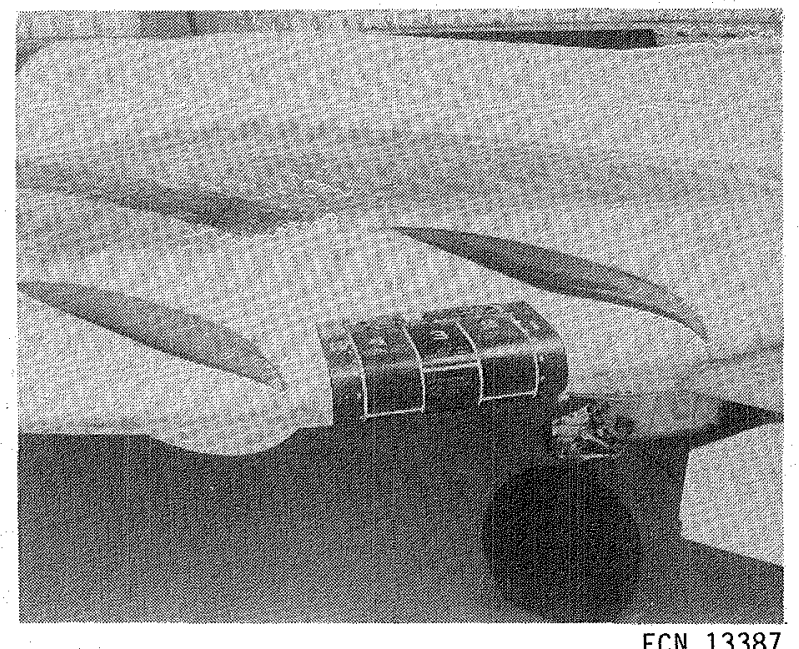

ECN 13387

(c) Shuttle vertical stabilizer leading edge test article mounted on F-15A-2 right wing.

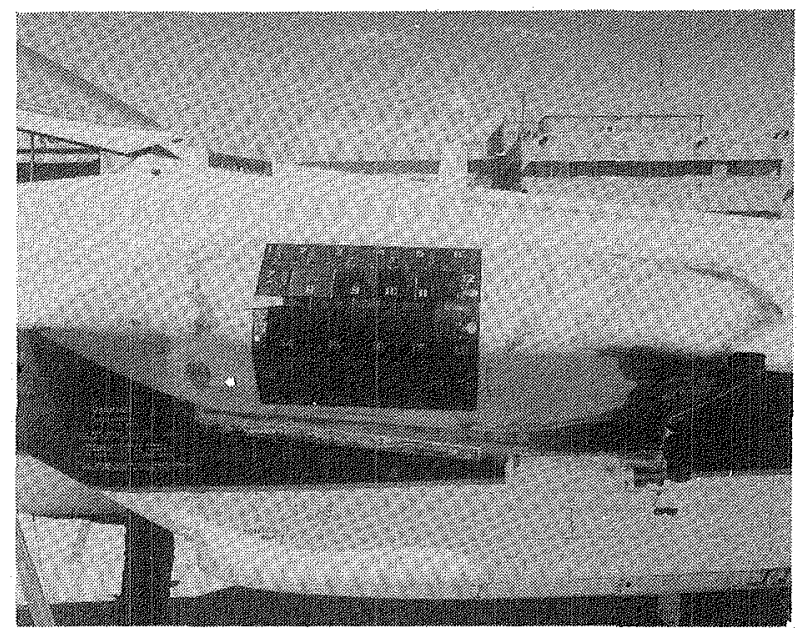

ECN 13386

(d) Shuttle wing glove test article mounted on F-15A-2 left wing glove (side view).

Fig. 12 Concluded. 


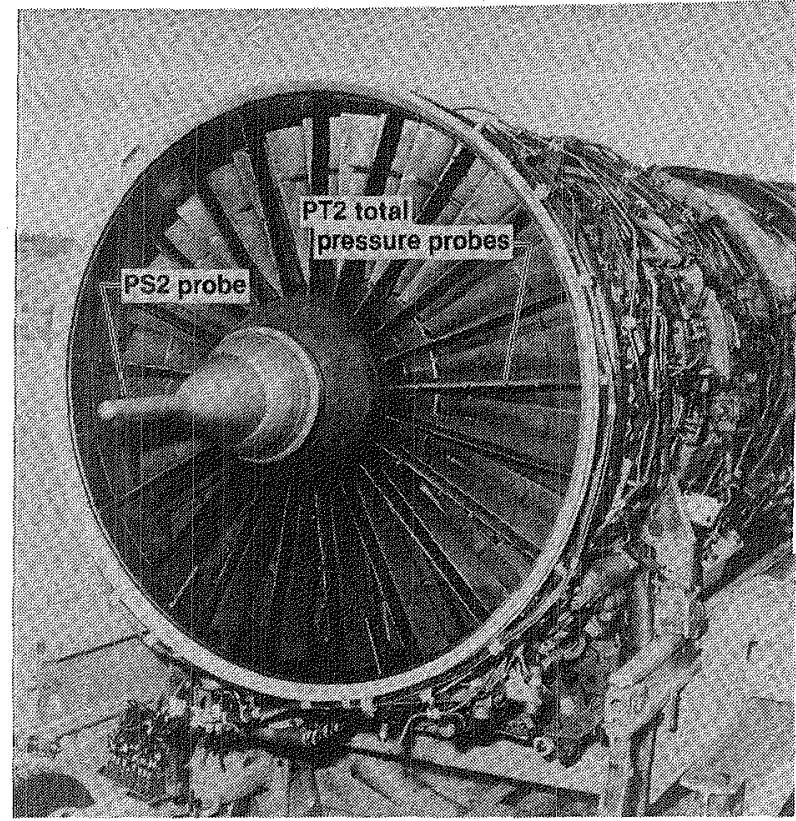

ECN 14251

(a) Engine-inlet static pressure (PS2) and fan inlet total pressure (PT2) probes at engine face.

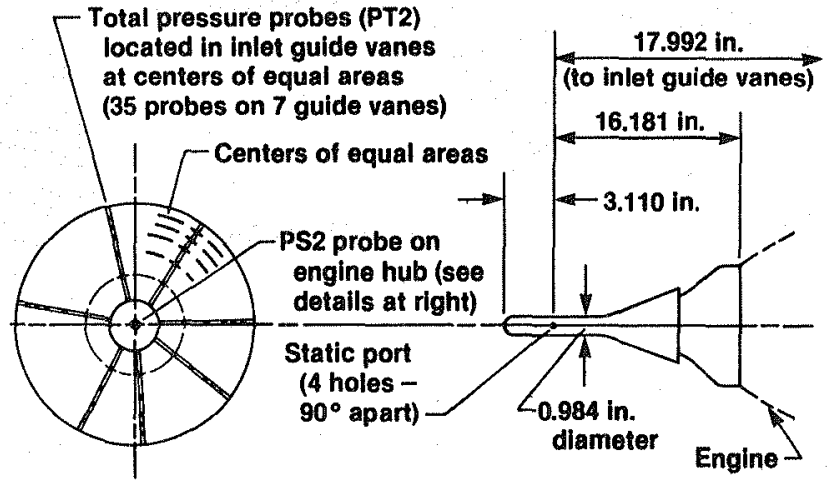

View looking at engine face (not to scale)

PS2 nose probe

(b) Engine-inlet pressure instmumentation.

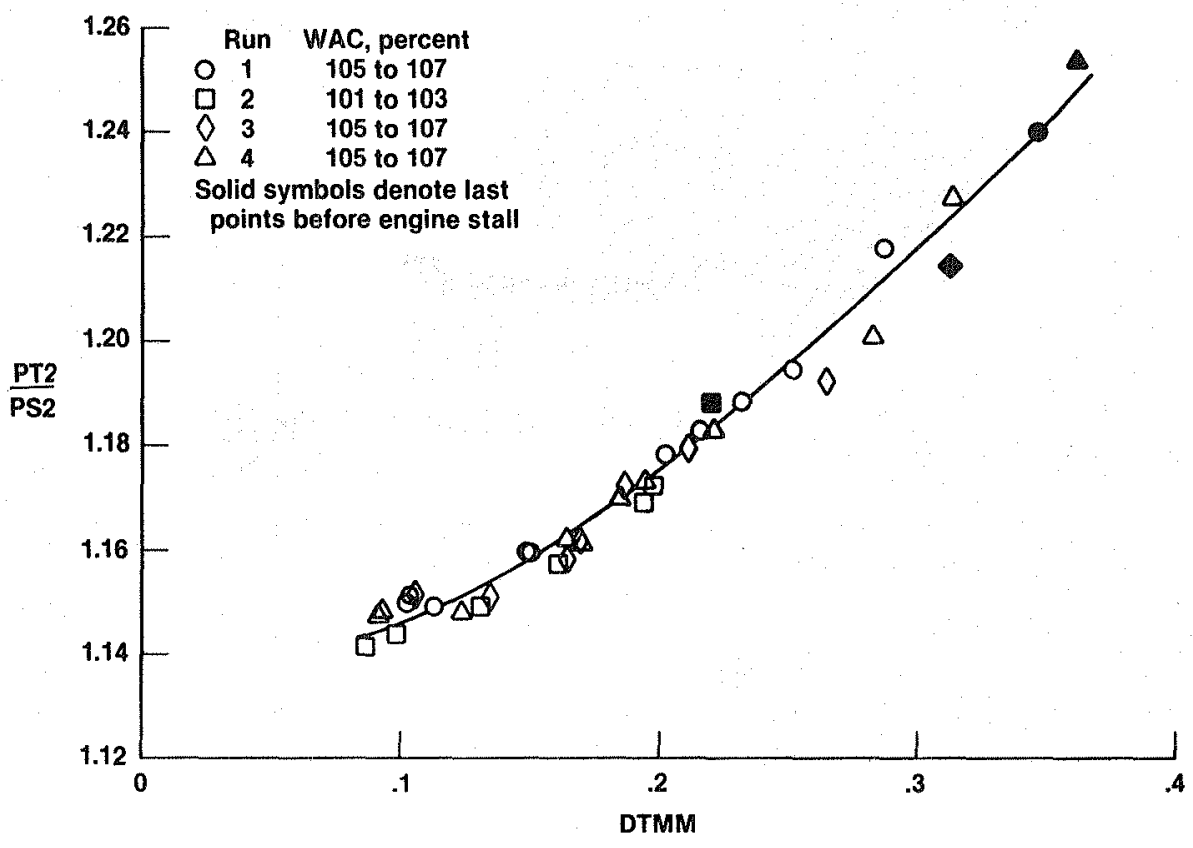

(c) Maximum-minimum total pressure distortion factor.

Fig. 13 Engine-inlet static pressure experiment. 


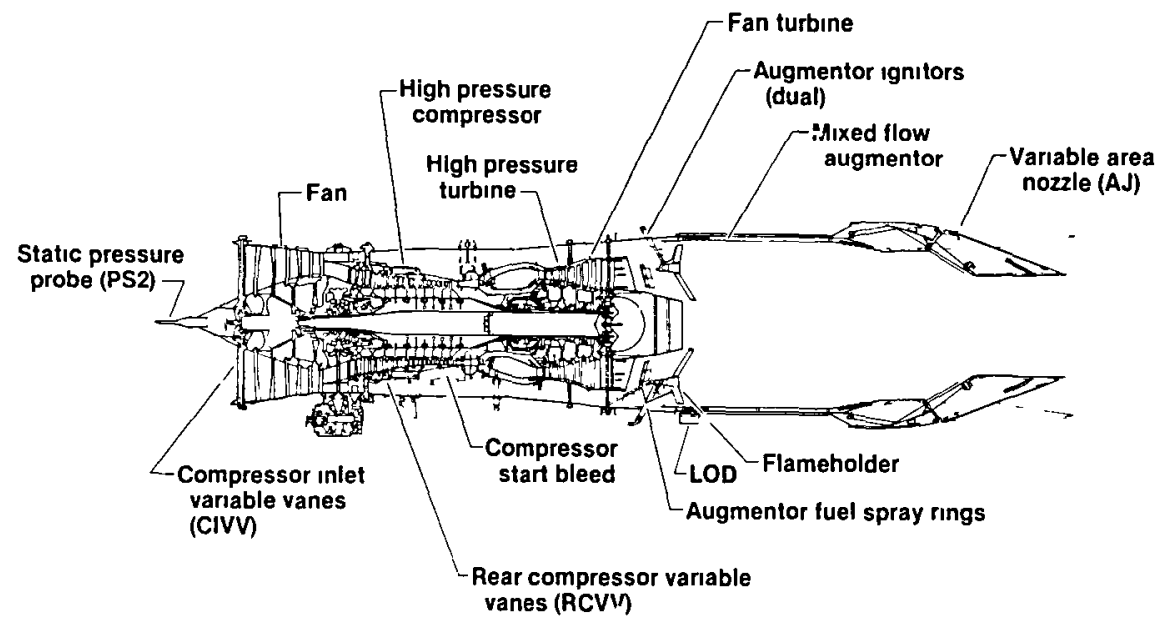

(a) Section view of F100 engine used in flight evaluation.

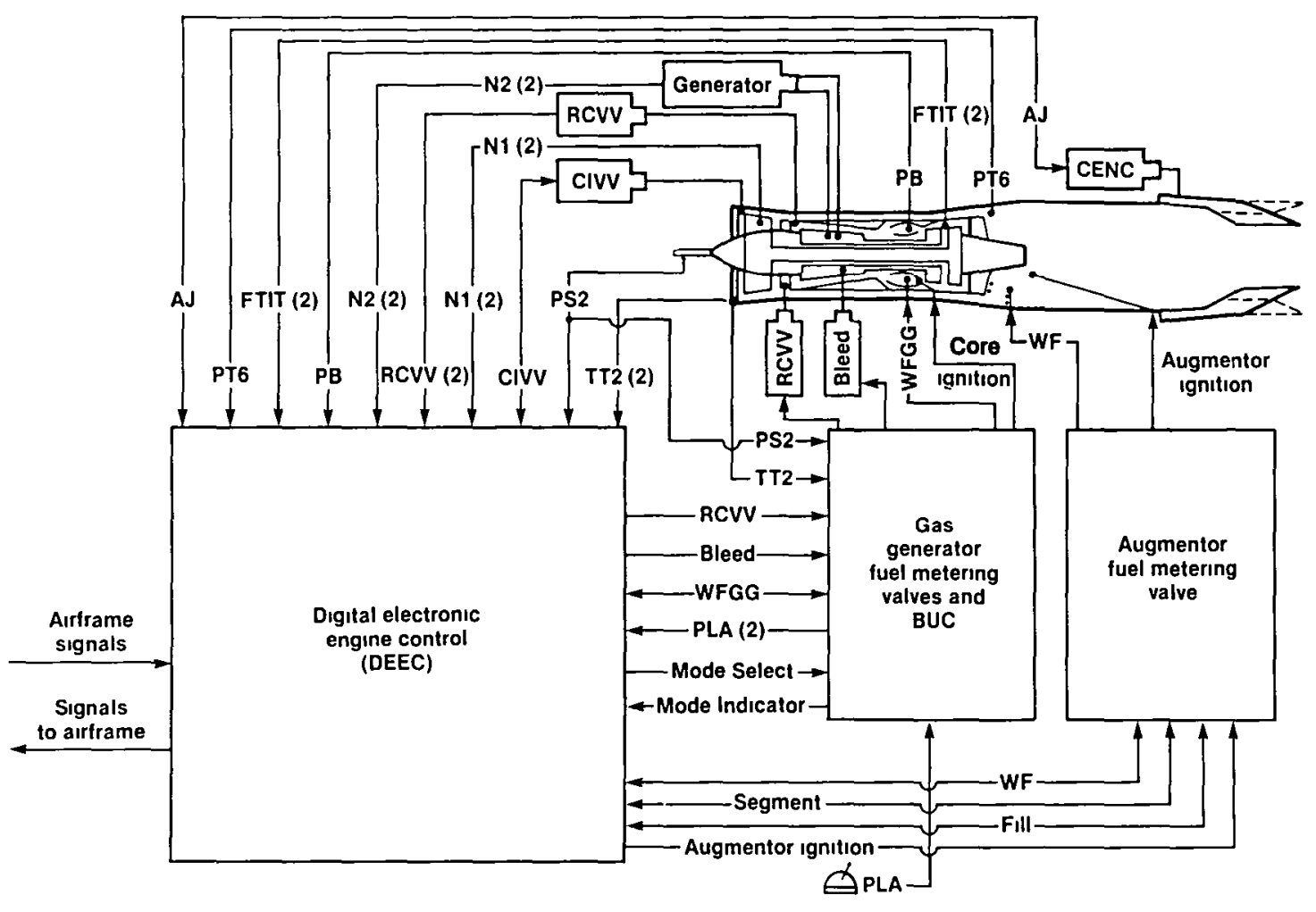

(b) DEEC system dragram.

Fig. 14 DEEC research project. 


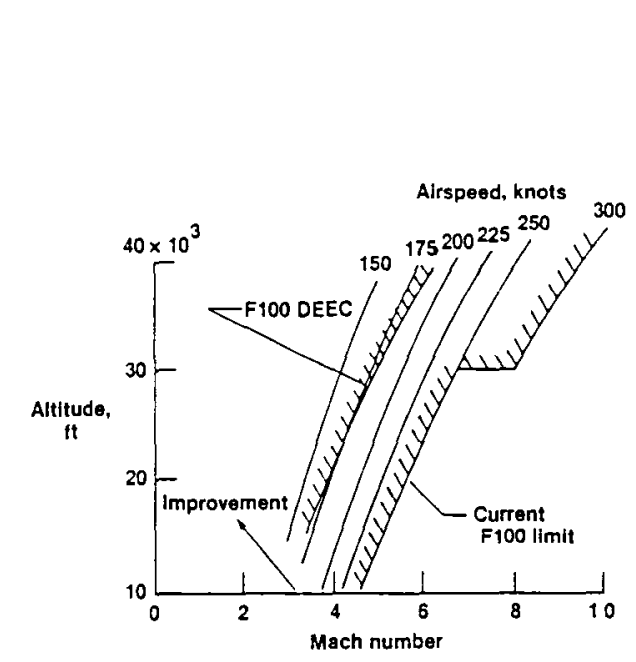

(c) Results of DEEC spool-down arrstart tests.

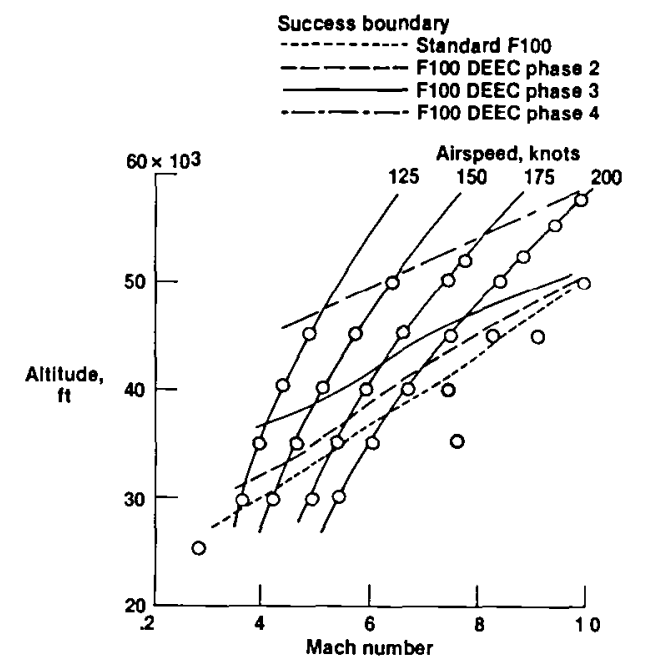

(d) Test results for idie-to-maximum power throttle transients.

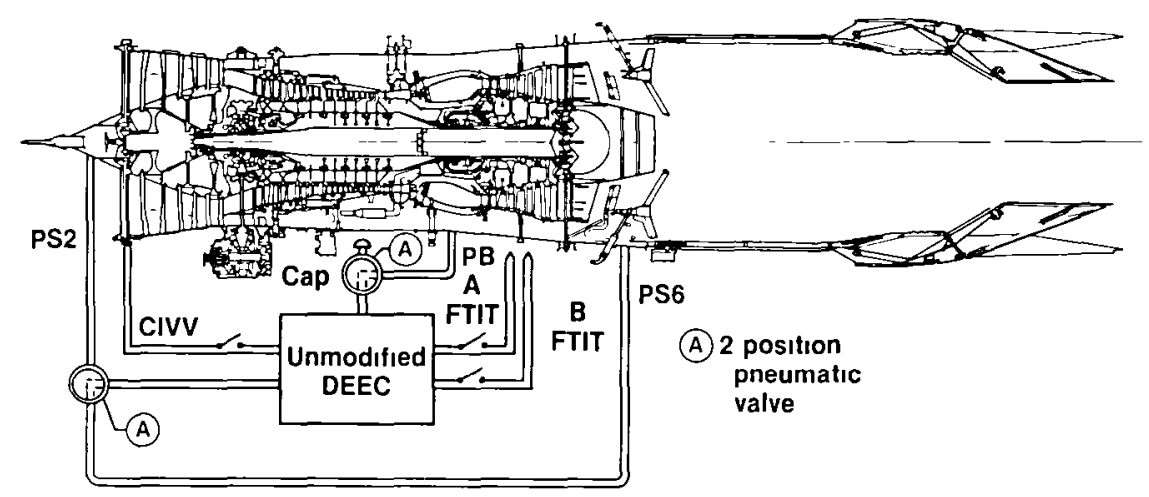

(e) Fault detection and accomodation modrfications on $F 100$ engrne.

Sensor fallures

- Steady state power

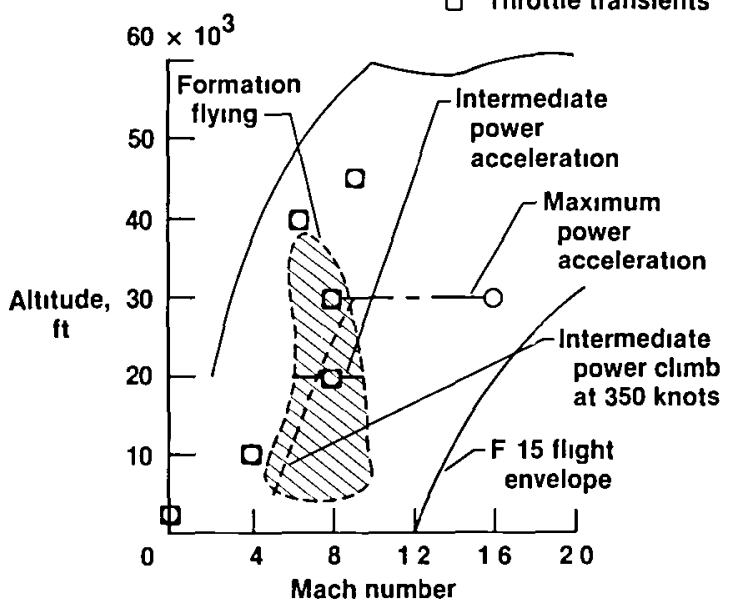

(f) Fault detectron and accommodation test points.

Fig. 14 Concluded. 


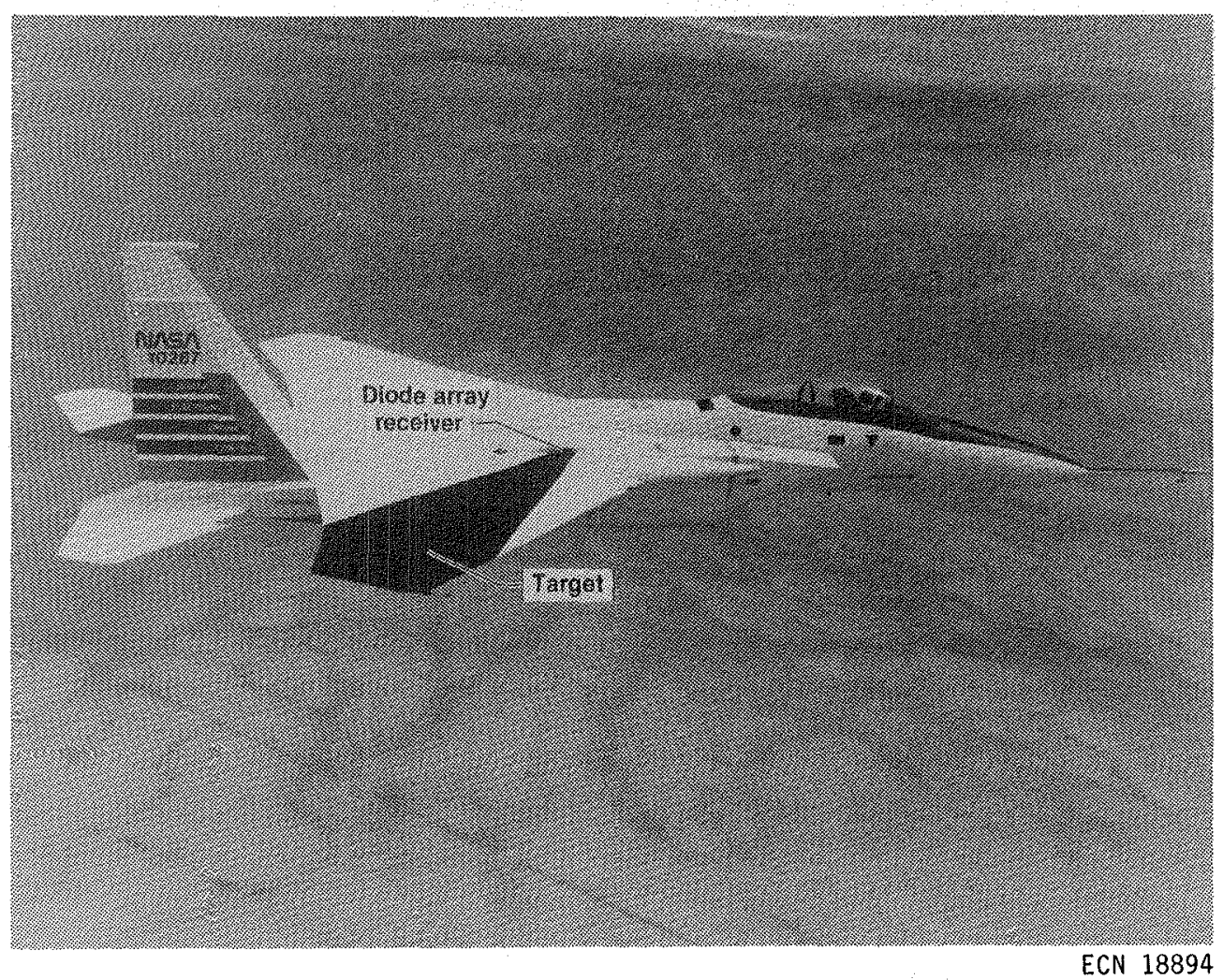

(a) F-15A-8 airplane with deflection measuring system installed on right wing.

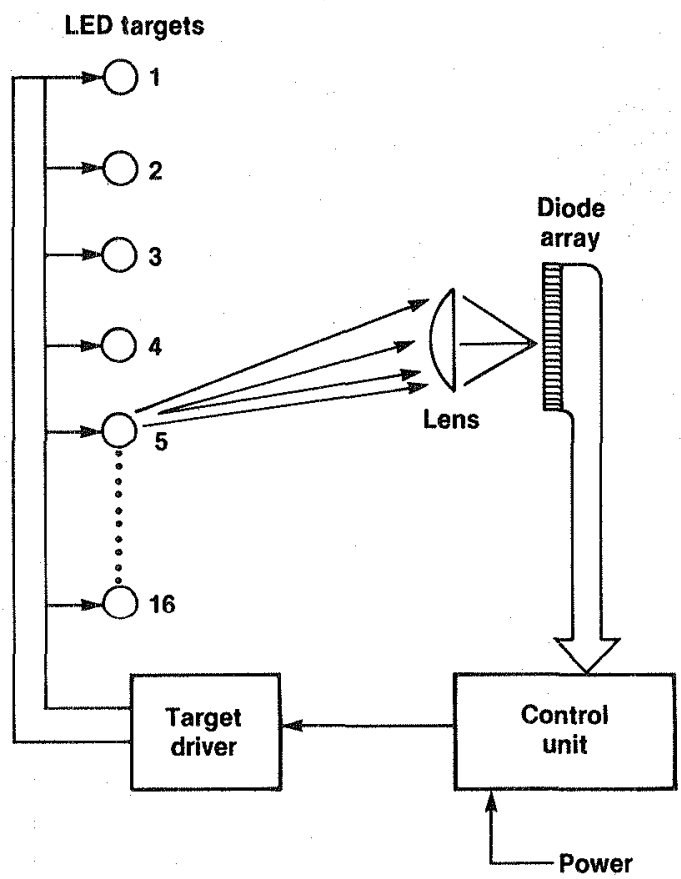

(b) Deflection measuring system schematic.

Fig. 15 Deflection measuring system evaluation. 


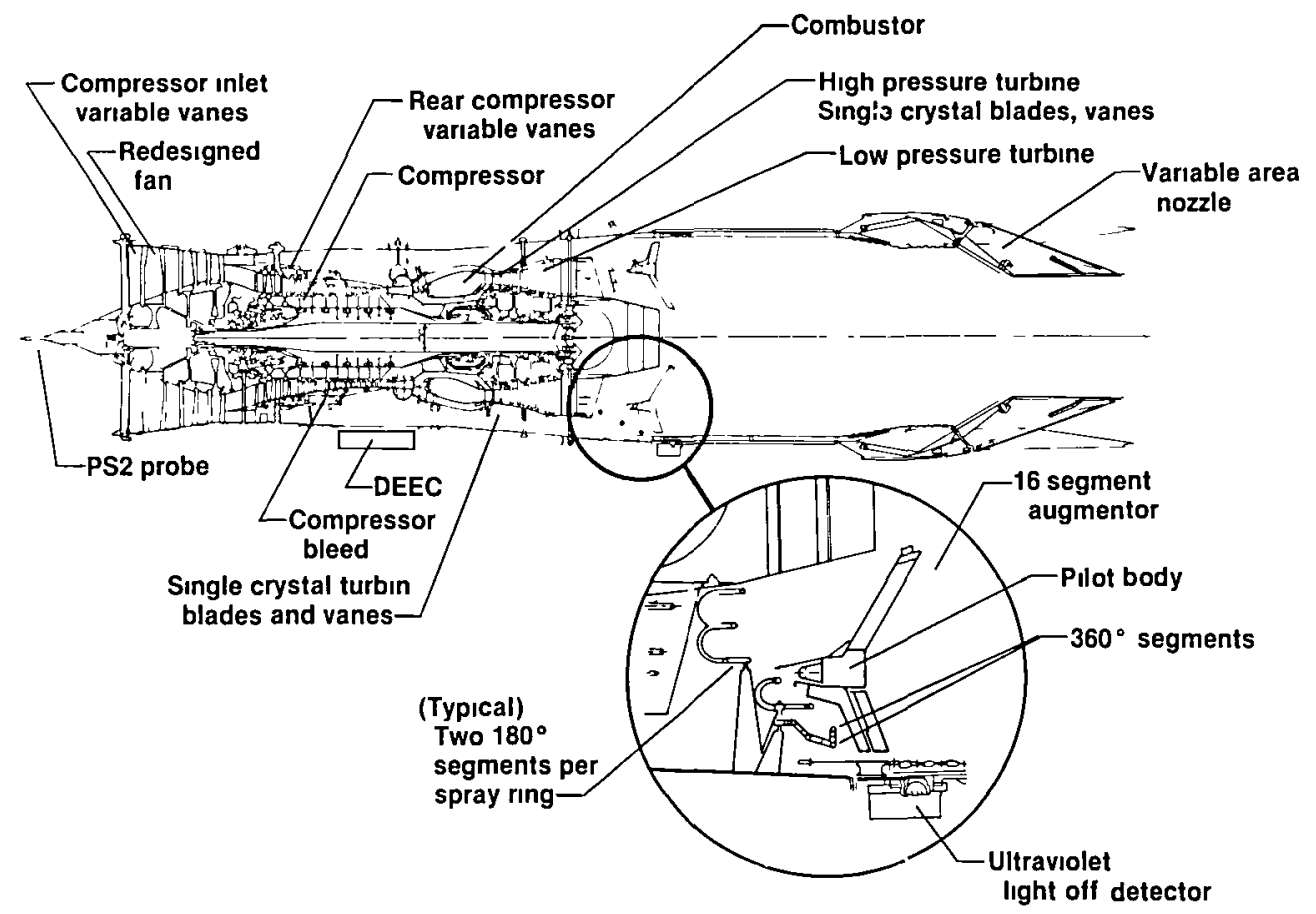

(a) Sectron view of engine showrng advanced features.

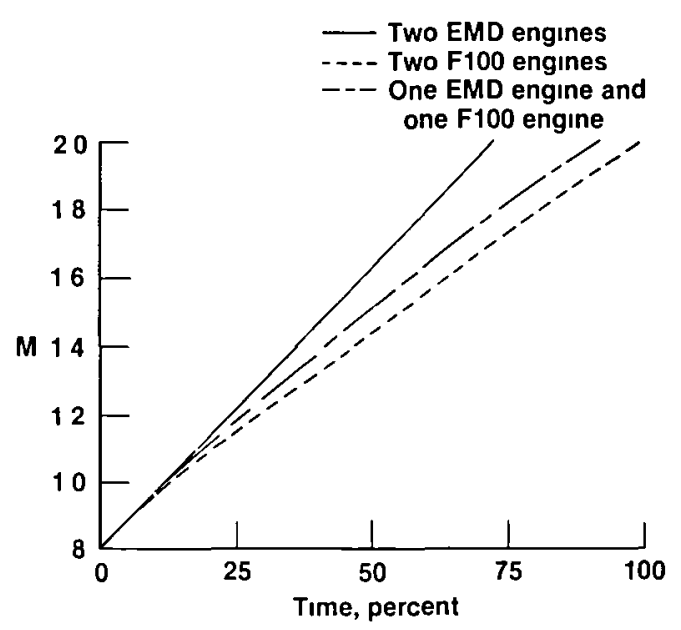

(b) Comparson of 40,000-ft level acceleratzons at maximum power and standard day conditions.

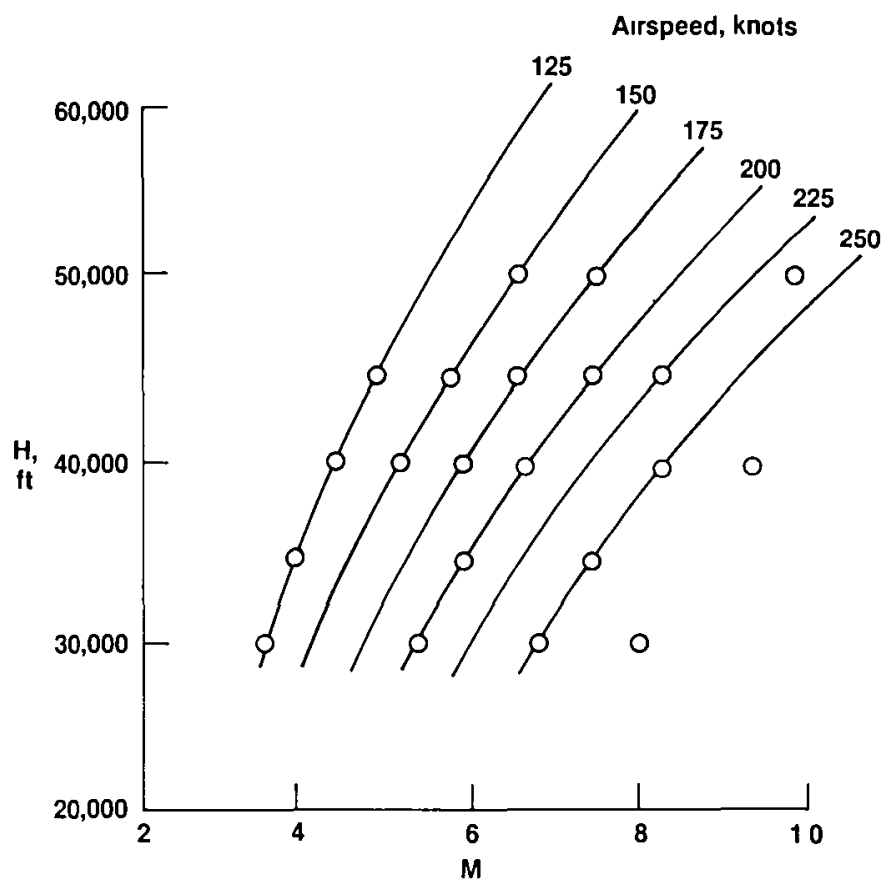

(c) Successful idle-to-maxtmum power throttle transients.

Fig. 16 F100 EMD evaluation. 


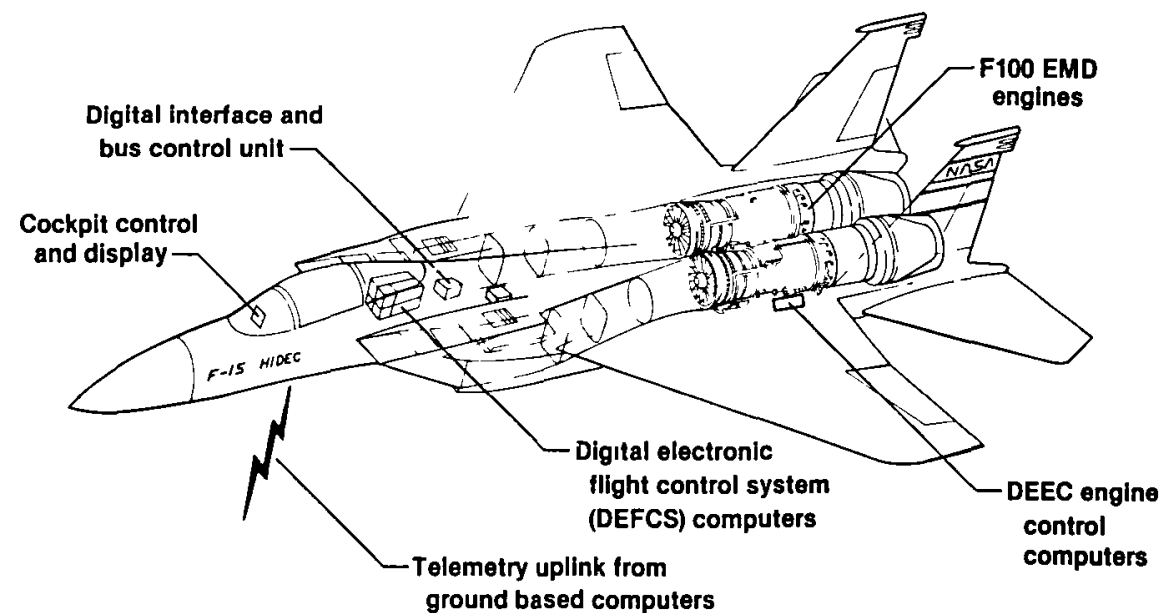

(a) Features of F-15 HIDEC research airplane.

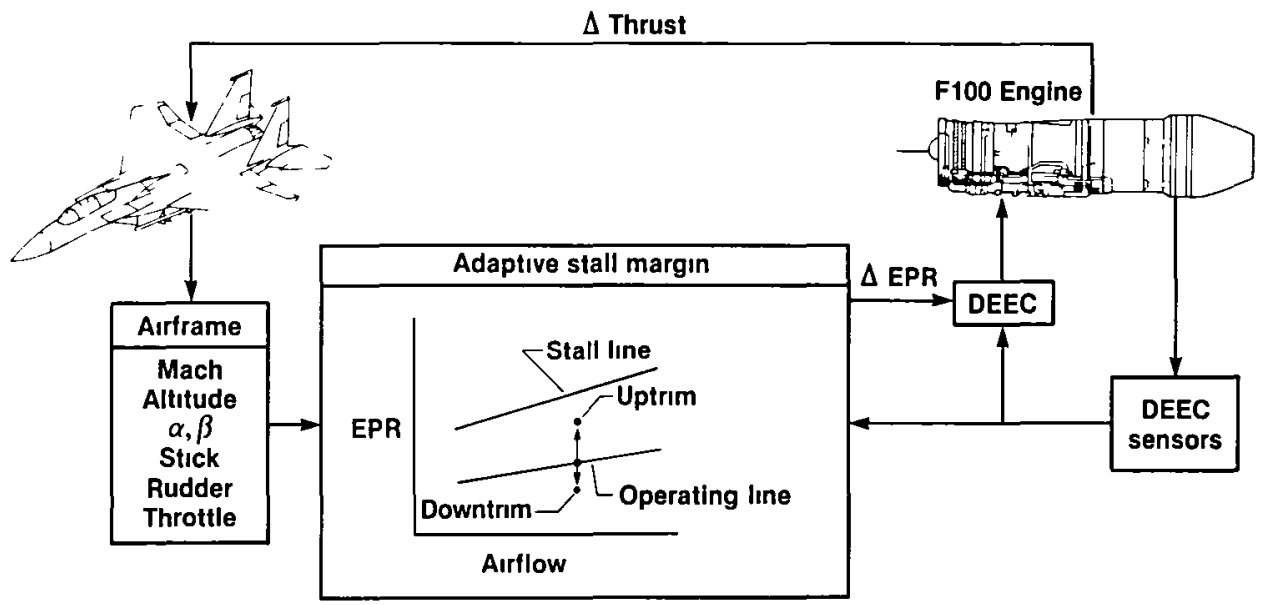

(b) ADECS.

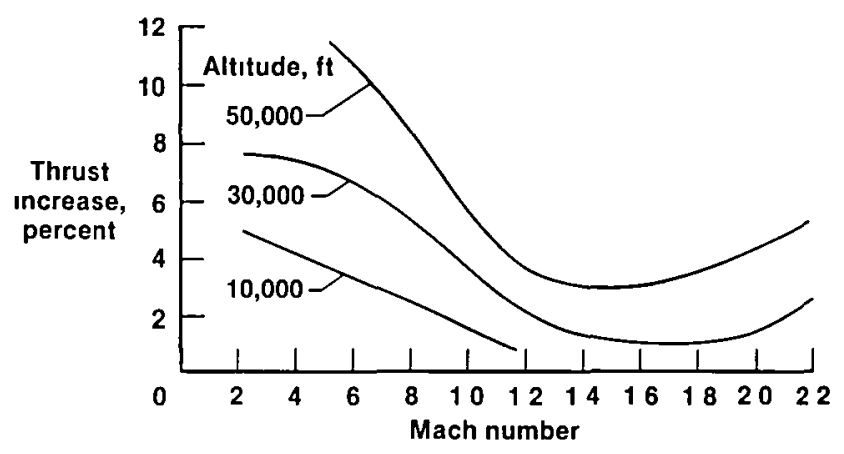

(c) Predicted thrust increase for ADECS mode at maximum power.

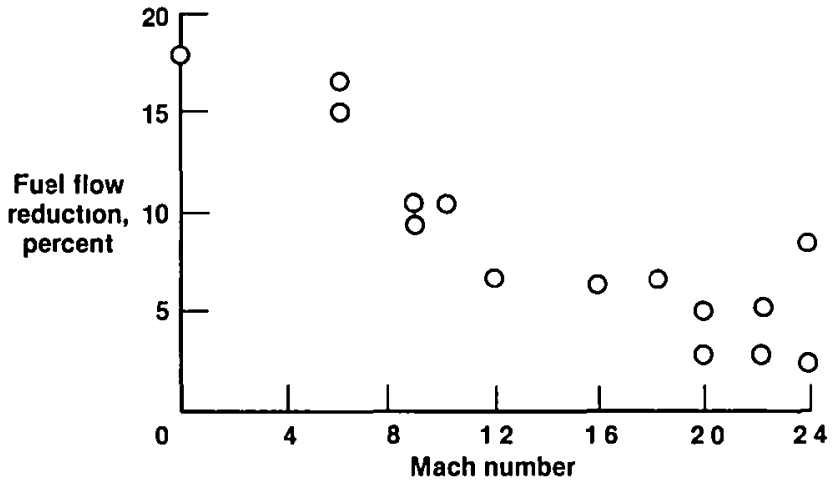

(d) Predicted reduction in fuel flow with engine pressure ratio uptrim to obtain nonuptrinoned maximun thrust.

Fig. 17 HIDEC project. 


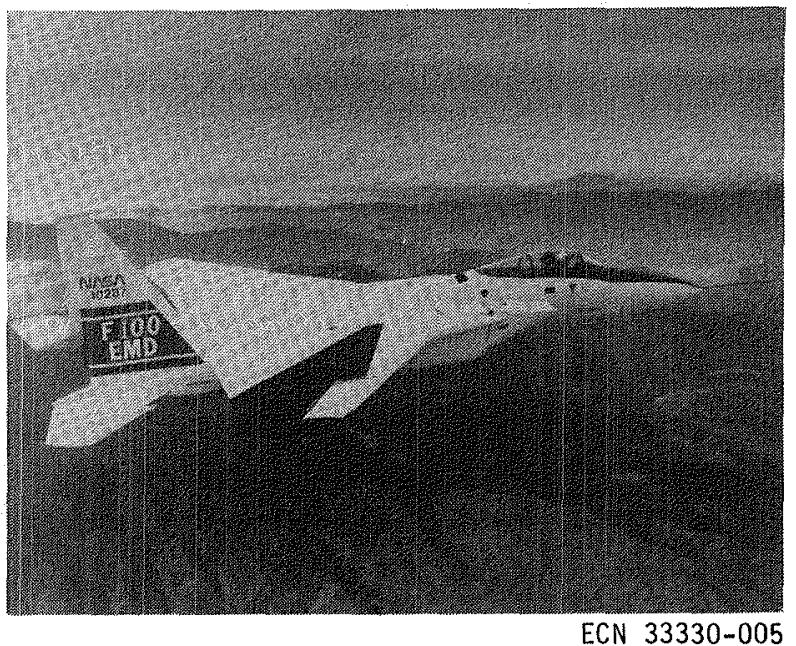

(a) Supersonic laminar flow glove.

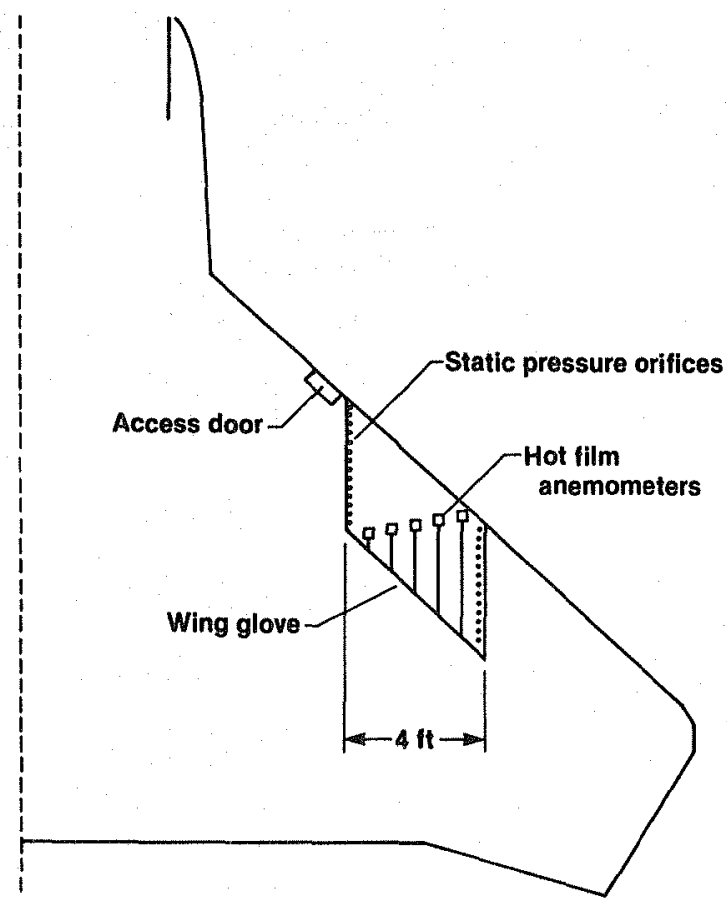

(b) Wing glove showing instrumentation.

Fig. 18 Supersonic laminar flow experiment.

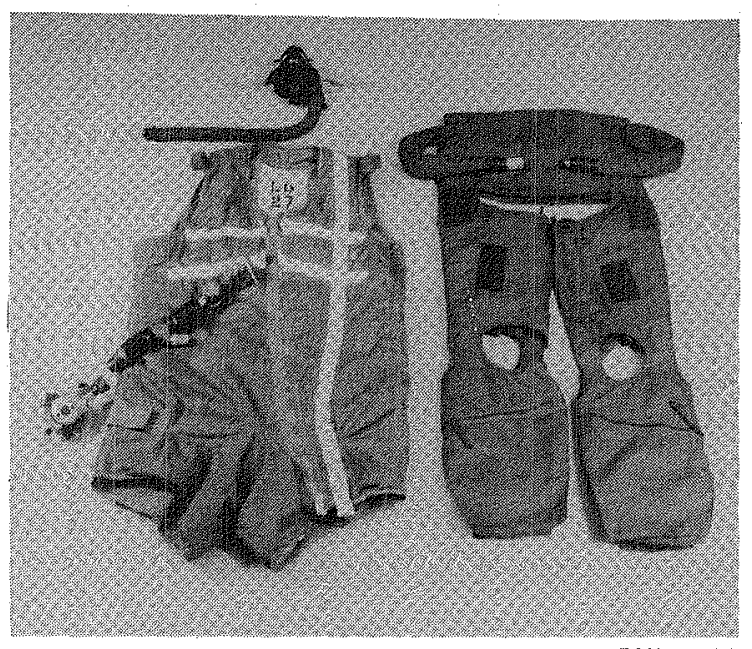

ECN 9181

(a) Pressure jerkin and dual-bladder antigravity suit trousers.

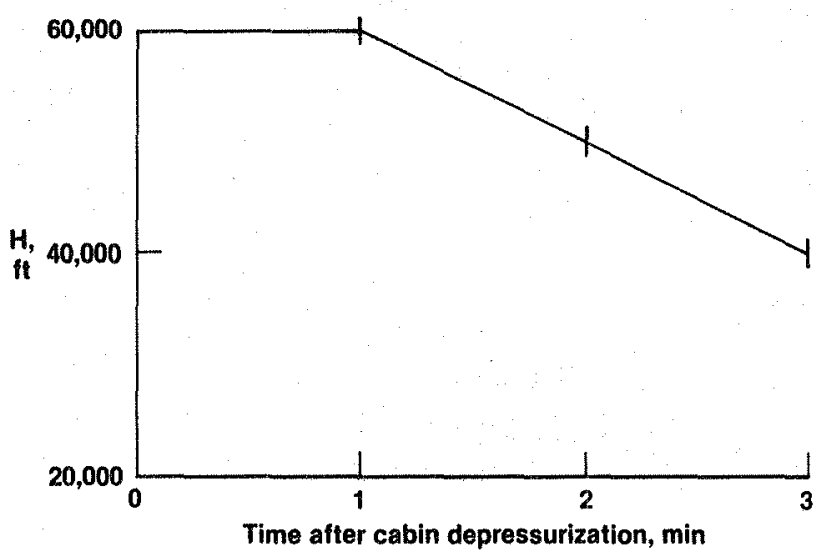

(b) Pressure jerkin altitude envelope.

Fig. 19 Royal Air Force high-altitude partial pressure protective assembly. 


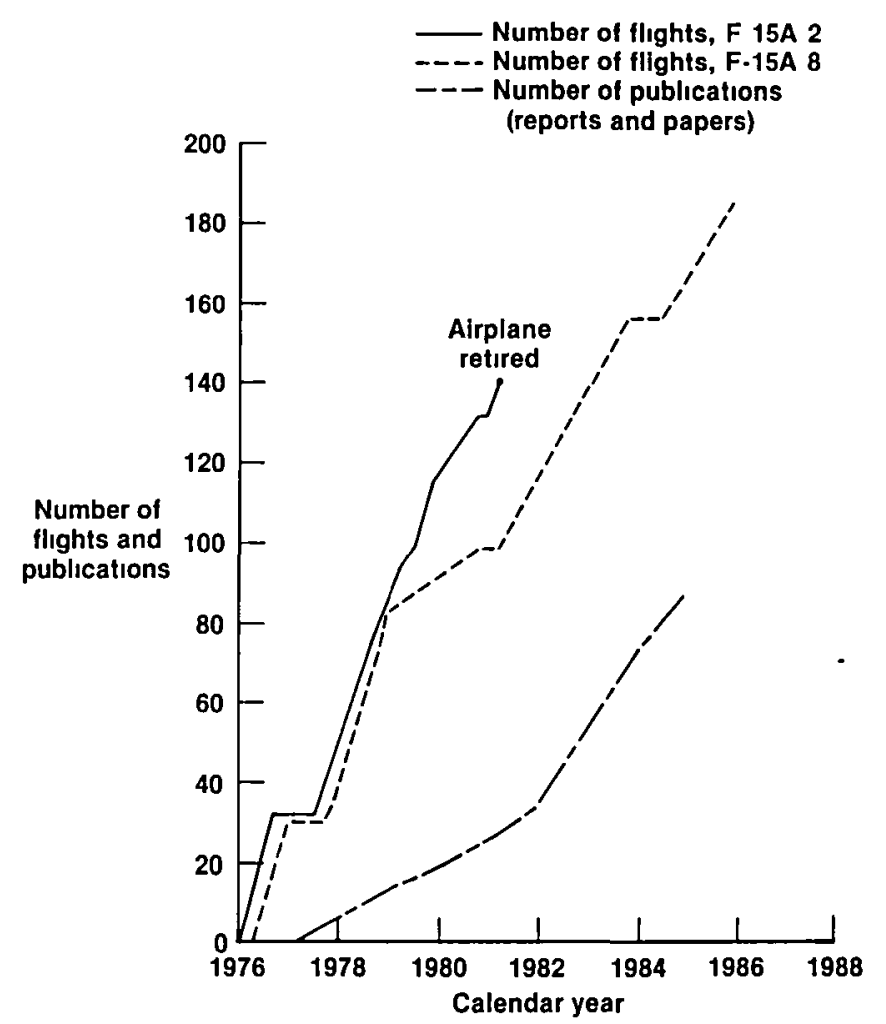

Fig. $20 \quad F-15$ research program flight and publication rates. 


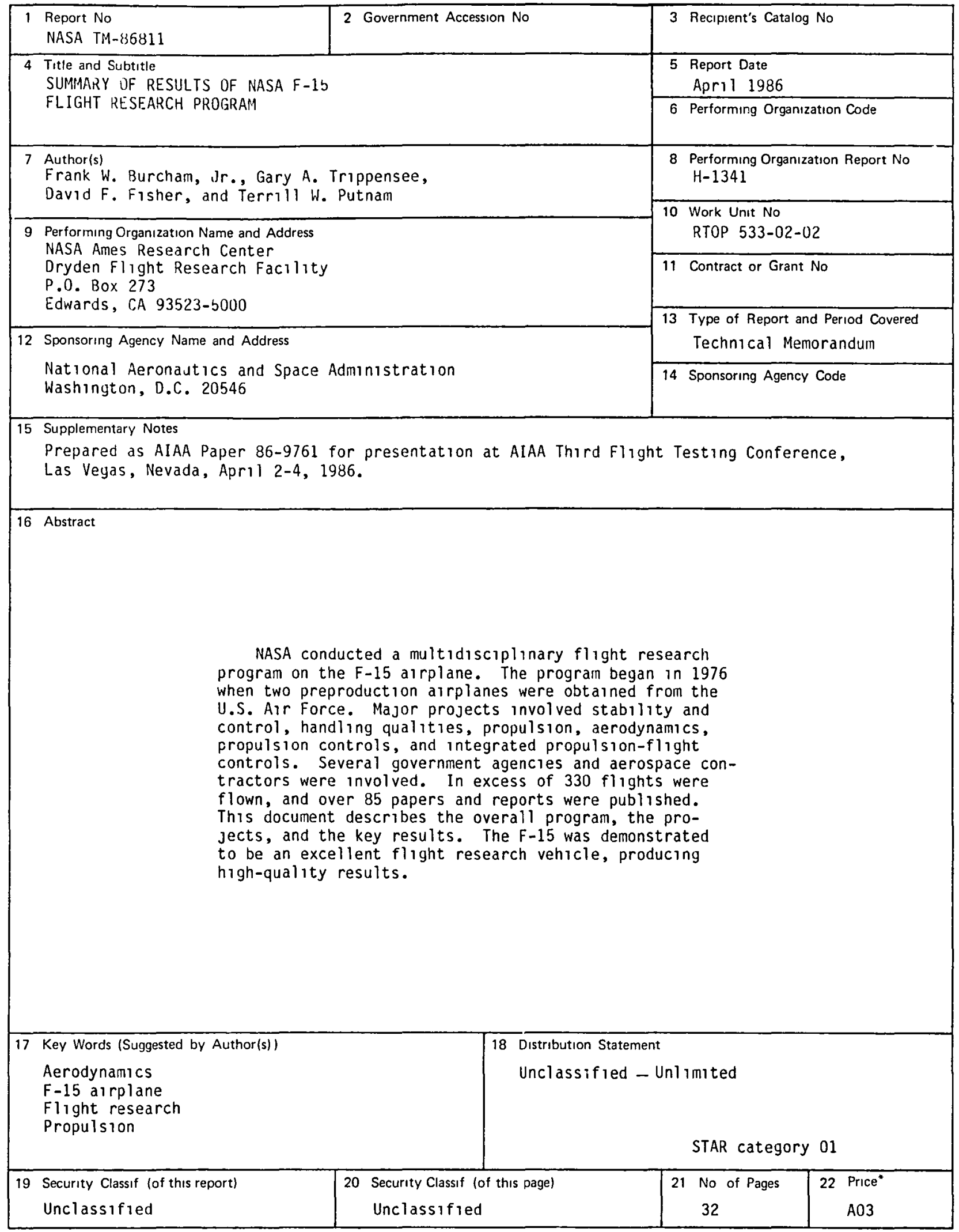

*For sale by the National Technzcal Information Service, Springfield, Virginia 22161. 
End of Document 